ONC-2013-00767. Revisión

\title{
Novel CTCF binding at a site in exon1A of BCL6 is associated with active histone marks and a transcriptionally active locus
}

Ana Batlle-López ${ }^{1,2}$, María G. Cortiguera ${ }^{1,2}$, Manuel Rosa-Garrido ${ }^{1,3}$, Rosa Blanco ${ }^{1}$, Elida del Cerro ${ }^{2}$, Verónica Torrano ${ }^{1,4}$, Simon D. Wagner ${ }^{5}$ and M. Dolores Delgado ${ }^{1}$

${ }^{1}$ Instituto de Biomedicina y Biotecnología de Cantabria (IBBTEC) and Departamento de Biología Molecular, Universidad de Cantabria, CSIC, SODERCAN, Santander, Spain.

${ }^{2}$ Servicio de Hematología, Hospital U. Marqués de Valdecilla, and IFIMAV-FMV, Santander, Spain

${ }^{3}$ Present Address: Department of Anesthesiology, David Geffen School of Medicine at UCLA, United States

${ }^{4}$ Present Address: Proteomics Unit. CIC bioGUNE. Bizkaia Technology Park, 801 building 48160, Derio. Spain

${ }^{5}$ Department of Cancer Studies and Molecular Medicine and MRC Toxicology Unit, University of Leicester, Lancaster Road, Leicester LE19HN, UK

Correspondence: Professor M. Dolores Delgado, IBBTEC, C/Albert Einstein 22, PCTCAN, 39011-Santander Spain. Tel: 34 942-201998. Email: delgadmd@unican.es or Dr. Simon Wagner, Department of Cancer Studies and Molecular Medicine and MRC Toxicology Unit, University of Leicester, Lancaster Road, Leicester LE19HN, UK. Email: sw227@leicester.ac.uk

Running Title: Epigenetic regulation of BCL6 by CTCF 


\section{Abstract}

BCL6 is a zinc finger transcriptional repressor, which is highly expressed in germinal centre B-cells and is essential for germinal centre formation and T-dependent antibody responses. Constitutive BCL6 expression is sufficient to produce lymphomas in mice. Deregulated expression of BCL6 due to chromosomal rearrangements, mutations of a negative autoregulatory site in the BCL6 promoter region and aberrant post-translational modifications, have been detected in a number of human lymphomas. Tight lineage and temporal regulation of BCL6 is, therefore, required for normal immunity and abnormal regulation occurs in lymphomas. CCCTC-binding factor (CTCF) is a multi-functional chromatin regulator, which has recently been shown to bind in a methylation sensitive manner to sites within the BCL6 first intron. We demonstrate a novel CTCF binding site in BCL6 exon1A within a potential CpG island, which is unmethylated both in cell lines and primary lymphoma samples. CTCF binding, which was found in BCL6 expressing cell lines, correlated with the presence of histone variant $\mathrm{H} 2 \mathrm{~A} . \mathrm{Z}$ and active histone marks, suggesting that CTCF induces chromatin modification at a transcriptionally active BCL6 locus. CTCF binding to exon1A was required to maintain BCL6 expression in germinal centre cells by avoiding BCL6 negative autoregulation. Silencing of CTCF in BCL6 expressing cells reduced BCL6 mRNA and protein expression, that is sufficient to induce B cell terminal differentiation toward plasma cells. Moreover, lack of CTCF binding to exon1A shifts the BCL6 local chromatin from an active to a repressive state. This work demonstrates that, in contexts in which BCL6 is expressed, CTCF binding to BCL6 exon1A associates with epigenetic modifications indicative of transcriptionally open chromatin.

Keywords: CTCF, BCL6, lymphoma, germinal centre, epigenetics 


\section{INTRODUCTION}

BCL6 is a transcriptional repressor, which plays important roles in normal B-cell development and in lymphomas. BCL6 is required for germinal centre formation and Tdependent antibody responses ${ }^{1}$ (reviewed in ref. $^{2}$ ) and must be down-regulated for terminal differentiation to plasma cells to occur ${ }^{3,4}$. BCL6, widely considered as a master regulator of the germinal centre reaction, inhibits genes involved in DNA damage (TP53 and ATR), cell cycle (CCND2, CDKN1B and CDKN1A), B cell activation (NKFB1, CD80, CD69) and plasma cell differentiation (BLIMP1) $)^{5}$ BCL6 deregulation due to translocations occurs in a variety of B-cell lymphomas (reviewed in ref. ${ }^{6}$ ) and BCL6 overexpression induces lymphomas, similar to human diffuse large B-cell lymphoma, in mice ${ }^{7}$. Normal BCL6 expression is tightly controlled through well-described transcriptional ${ }^{8-11}$ and posttranslational ${ }^{12-14}$ mechanisms. In our previous studies, a short region on the BCL6 first non-coding exon1A was associated with high-level transcriptional activity in reporter assays $^{15,16}$. Bioinformatic analysis of that region showed high transcription factor binding site density including a putative binding site for the CCCTC-binding factor (CTCF). CTCF was recently shown to bind unmethylated $\mathrm{CpG}$ islands within BCL6 intron 1 in a plasma cell line that does not express BCL6 ${ }^{17}$. However, in a BCL6 expressing Burkitt's lymphoma cell line there was less CTCF binding at these intronic sites associated with increased methylation ${ }^{17}$. The aim of the present study was to analyse the novel CTCF binding site found in a CpG island in BCL6 exon1A and its possible biologic and mechanistic roles in BCL6 regulation in either BCL6 expressing or non-expressing cell lines and in primary cells from patients with different lymphoid neoplasms.

CTCF is a multifunctional regulator that has key roles in inducing and supporting chromatin interactions. CTCF activities include transcriptional repression or activation, chromatin insulation, regulation of genomic imprinting and epigenetic regulation of a number of target genes (for reviews see ${ }^{18,19}$ ). CTCF contains a DNA-binding domain 
composed of 11 zinc-fingers able to bind many different sequences. Genome-wide analysis identifies about 40000 CTCF binding sites depending on the cell type analysed $^{20,21}$ and additional studies reveal consensus motifs for CTCF binding sites in different organisms ${ }^{18}$. In the ENCODE project, the genome-wide binding location and occupancy of CTCF has recently been refined by several groups ${ }^{22,23}$. The most studied CTCF property is its ability to bind insulator sequences ${ }^{24}$, controlling the boundaries between silent heterochromatin and active euchromatin ${ }^{25,26}$. CTCF has an essential role in the global chromatin structure organization through the facilitation of long-range interactions and chromatin looping ${ }^{19,24}$. More than twenty CTCF partners have been identified so far, including cohesin proteins ${ }^{27,28}$, chromatin constituents as the histone variant $H 2 A . Z^{29}$, transcription factors such as $U_{B F}^{30}$ and others (reviewed $\mathrm{in}^{18}$ ). CTCF is involved in different aspects of epigenetic regulation ${ }^{31}$ and regulates genes involved in cancer such as $\mathrm{MYC}^{32}, \mathrm{RB}^{33}, \mathrm{p} 53^{34}, \mathrm{p} 16\left(\mathrm{ref}^{35}\right)$ or $\mathrm{hTERT} \mathrm{T}^{36}$, frequently through epigenetic mechanisms $^{31}$. For instance, CTCF binds unmethylated DNA and blocks the spreading of the CpG methylation front on the RB promoter ${ }^{33}$.

Here we report a novel CTCF binding site occurring in a CpG island in BCL6 exon1A that is neither methylated in BCL6 expressing or non-expressing cell lines or in primary cells from patients with different lymphoid neoplasms. In vivo binding of CTCF at BCL6 exon1A occurs in association with active histone marks and CTCF protects against repressive marks in a transcriptionally active locus. Moreover, our results suggest that CTCF binding to exon1A is required to maintain BCL6 expression in germinal centre cells by avoiding BCL6 negative autoregulation. Indeed, CTCF silencing on those cells leads to BCL6 dowregulation that is sufficient to induce markers of plasma cells differentiation. 


\section{RESULTS}

\section{CTCF binds in vitro and in vivo to BCL6 exon1A}

A relatively short region on the $B C L 6$ first non-coding exon $1 A$, from +1 to +533 (relative to the transcription start site $^{37}$ ), was associated with high-level transcriptional activity in reporter assays ${ }^{15,16}$. In order to determine potential CTCF binding sites we utilised a database that was constructed using genome-wide experimental methods ${ }^{38}$. A CTCF binding site at BCL6 exon1A was predicted with high scores (Figure 1a) and this was confirmed by the recently updated database (http://insulatordb.uthsc.edu/) ${ }^{39}$.

In order to investigate CTCF binding at BCL6 exon1A, electrophoretic mobility shift assays (EMSA) were carried out. A 198 bp probe containing the CTCF binding site at BCL6 exon1A was generated by PCR amplification and incubated with nuclear extracts from HEK293T cells transfected with CTCF expression vectors. Extracts from CTCF transfected cells showed stronger binding to the BCL6 probe compared to extracts from mock-transfected cells or cells transfected with a CTCF N-terminal domain expression vector (Figure 1b lanes 1-3). The binding specificity was demonstrated by incubating the nuclear extracts with a specific anti-CTCF antibody. A supershifted band was observed (asterisk in Figure 1b lane 4) while no supershift was found with an anti-actin antibody (Figure 1b lane 5). The known MYC-N site was used as positive control for CTCF binding (Figure $1 \mathrm{~b}$ left panel). To further delimitate the CTCF binding site, an EMSA using a double-stranded oligonucleotide of 80 nt containing the "core" 20 nt sequence predicted by the CTCFBS data base was performed, showing specific CTCF binding (supplementary Figure S1). Therefore, CTCF interacts in vitro with the predicted binding site at the BCL6 exon1A.

Chromatin immunoprecipitation (ChIP) experiments were employed to investigate in vivo occupancy of the BCL6 exon1A site by CTCF. In all the experiments, CTCF binding to the H42.1 site in the rDNA repeats ${ }^{30}$ was used as positive control, while the MYC-H.1 site 
was used as negative control (Figure 2a). ChIP assays using two different anti-CTCF antibodies showed CTCF occupancy of the BCL6 exon1A site in Ramos, a Burkitt's lymphoma derived cell line, extensively used as cell model system for germinal centre (see details of the cell lines in supplementary table S1). The variant histone H2A.Z has been reported to be a CTCF partner ${ }^{29}$ and to colocalize with CTCF in genome wide studies ${ }^{25}$. We therefore asked whether $\mathrm{H} 2 \mathrm{~A} . \mathrm{Z}$ was detected in the BCL6 regulatory region. ChIP analysis revealed specific accumulation of $\mathrm{H} 2 \mathrm{~A} . \mathrm{Z}$ at the CTCF binding site of BCL6 exon1A (Figure 2b). The analysis of different regions of the BCL6 gene (amplicons indicated in Figure 1a) demonstrated high CTCF enrichment with the primers covering the predicted CTCF binding in exon1A in Ramos cells (Figure 2c).

We next studied whether CTCF occupancy was modified in lymphoma cell lines with different levels of BCL6 expression (see western blot in supplementary Figure S2a). We compared CTCF in vivo binding in Ramos (a germinal centre cell line expressing high levels of BCL6), MutullI (also a germinal centre cell line but which does not express BCL6) and K562 (a BCL6 negative myeloid cell line). ChIP analysis revealed CTCF occupancy of the BCL6 exon1A site in Ramos but not in Mutulll or K562 cells (Figure 2d). High CTCF occupancy was observed in myeloid K562 cells at BCL6 intronic CTCF binding sites (amplicons 6 and 7) already described by Lai et $\mathrm{al}^{17}$. Interestingly, CTCF binding to exon1A was not detected in BCL6 non-expressing cell lines (supplementary Figure S1a and $\mathrm{S} 1 \mathrm{~b})$, indicating that CTCF is preferentially bound to exon1A when BCL6 is highly expressed. This finding suggests that CTCF binding at the exon $1 \mathrm{~A}$ site and not to the intronic sites is functionally important in germinal centre cells.

\section{CTCF knock-down reduces BCL6 expression in germinal centre B cells and induces markers of plasma cells differentiation}

To determine the CTCF regulatory effect on BCL6 expression, we knocked down CTCF in 
two different BCL6 expressing germinal centre lymphoma cells. Silencing of CTCF mRNA in DG75 was achieved 48 hours after transfection with the pRS-CTCF vector and this effect was maintained until, at least, 96 hours (Figure 3a). CTCF knockdown caused down-regulation of both BCL6 mRNA (Figure 3a) and protein (Figure 3b) expression. Similar results were obtained upon viral infection of Ramos cells i.e. CTCF silencing was accompanied with reduced BCL6 mRNA and protein expression (Figure 3c and 3d). BCL6 expression has been induced by silencing of CTCF in BCL6 negative plasma cells ${ }^{17}$ but no induction was observed in BCL6 negative K562 myeloid cells (Figure 3e and 3f).

For a B-cell to exit the germinal centre BCL6 expression is downregulated, leading to changes in BCL6 target gene expression. In our model, when BCL6 expression was dowregulated through CTCF inhibition, expression of two BCL6 target genes CCND2 and BLIMP1 was significantly increased (Figure 3g). IRF4, a marker for plasma cell differentiation was also upregulated (Figure $3 g$ ). Thus, our results indicate that CTCF is required to maintain BCL6 expression in germinal centre cells and its downregulation is sufficient to induce B cell terminal differentiation toward plasma cells.

\section{CTCF counteracted the negative autoregulation of BCL6 at exon1A}

To determine whether CTCF had any effect on transcriptional activity at the BCL6 promoter, luciferase assays were carried. A pGL3 reporter construct containing a BCL6 proximal promoter fragment including the exon1A region was co-transfected with two different CTCF expression vectors in DG75 lymphoma cells. Enforced expression of CTCF led to a reproducible increase in BCL6 reporter activity (Figure 4a). This effect required the full length-CTCF protein, as co-transfections with individual CTCF domains (zinc-finger or C-terminal domains) had no significant effect on the reporter gene activity (Figure 4a). Altogether our results suggest that, in BCL6 expressing germinal centre cells, CTCF binding to the exon1A might be involved in the transcriptional up-regulation of BCL6. 
BCL6 bound to high affinity sites in exon1A (see Figure 1a) is known to repress its own transcription ${ }^{8,9,40}$. The location of the exon1A CTCF site suggests that it may be important in regulating BCL6, and speculatively CTCF binding might be required to prevent BCL6 negative autoregulation. To address this hypothesis we performed luciferase reporter assays in the BCL6-non expressing HEK293T cell line, examining a BCL6 promoter region that contains both the CTCF and the BCL6 autoregulatory sites (Figure 4b). That region showed a high transcriptional activity in basal conditions, and this activity was progressively reduced upon transfection with increasing dosis of a BCL6 expressing vector. Notably, the negative effect by BCL6 was significantly counteracted by cotransfection with CTCF in a dosis-dependent manner (Figure 4b). Taken together, these data suggest that CTCF binding to its exon1A site may be essential for protecting BCL6 from its own autorepression in germinal centre cells.

\section{CTCF binding to BCL6 exon1A is methylation-insensitive}

CTCF regulation of its target genes frequently involves epigenetic mechanisms, including DNA methylation ${ }^{31}$. To address whether CTCF binding to BCL6 exon1A was methylationsensitive, EMSAs were performed using probes that were unmethylated or fully methylated (Figure 5a). Band-shift results using either control or methylated probes were very similar, indicating that probe methylation does not alter CTCF binding (Figure 5b lanes 2 and 8 ). Therefore, CTCF showed in vitro methylation insensitive binding to the BCL6 exon1A site.

We speculated that CTCF might be regulating methylation at the BCL6 locus by controlling and impeding methylation progression, as it has been previously shown for other genes ${ }^{33,34,36}$. We therefore determined possible CpG islands in $20 \mathrm{~kb}$ of the BCL6 regulatory region using Methyl Primer Express software. The BCL6 exon1A region containing the CTCF binding site was located within a predicted CpG island (see sequence in Figure 1a). In order to find out if there was variation in methylation of this CpG 
island correlating with BCL6 expression in different cell lines and primary cells, we used bisulfite genomic sequencing to investigate the methylation status of the CpG dinucleotides located near the "core" CTCF binding site (see scheme in Figure 5c). Control for the bisulfite transformation assay and the ability to detect methylated DNA was performed (supplementary Figure S4). In all the cell lines evaluated, the CpG dinucleotides were unmethylated (Figure 5c). To further investigate the methylation status of that region, bisulfite treated genomic DNA from seven patients with a variety of B neoplasms were PCR amplified, cloned and sequenced. Neither of them showed methylation of any of the CpG dinucleotides (Figure 5c). Finally, no cytosine methylation was observed around the CTCF binding site after effectively silencing CTCF in DG75 cells (data not shown). Collectively these results indicate that differential methylation of the BCL6 exon1 regulatory region including the CTCF binding site, is not associated with the BCL6 expression regulation.

\section{CTCF binding associates with active histone marks and protects BCL6 exon1A against repressive marks}

Post-translational modifications of histones modifies the accessibility of chromatin, contributing to the recruitment of different protein complexes regulating transcription ${ }^{41,42}$. Given that CTCF may regulate the local epigenetic state of chromatin through mechanisms involving histone modifications ${ }^{30,34}$, we analyzed the presence of modified histones at exon1A in the BCL6 positive cell line, Ramos, and in the BCL6 non-expressing cell line, Mutulll (Figure 6a). Ramos cells showed a high enrichment of active chromatin marks, including histone $\mathrm{H} 3$ acetylation $(\mathrm{H} 3 \mathrm{Ac})$ and histone $\mathrm{H} 3$ lysine 4 dimethylation (H3K4me2). On the contrary, Mutulll cells showed less enrichment of active histone marks. ChIP experiments for repressive histone marks revealed lower H3K27me3 and especially H3K9me3 relative enrichment in Ramos compared to Mutulll cells (Figure 6a) 
(histone marks normalization are shown in supplementary Figure S5). CTCF binding, therefore, appears to associate with active marks in BCL6 expressing cells.

Finally, we investigated the effect of CTCF silencing on the local chromatin structure at the BCL6 exon1A. Ramos cells were infected with retrovirus prepared from pRS (control) and pRS-CTCF and ChIP assays for CTCF and modified histones were performed. As expected, a strong decrease of CTCF binding to BCL6 exon1A was found upon CTCF silencing (Figure $6 \mathrm{~b}$ left panel). A modest reduction in active marks (not shown) together with a strong enrichment of $\mathrm{H} 3 \mathrm{~K} 9 \mathrm{me} 3$ and $\mathrm{H} 3 \mathrm{~K} 27 \mathrm{me} 3$ repressive histones (Figure $6 \mathrm{~b}$ middle and right panels) was observed at BCL6 exon1A regulatory region in Ramos cells lacking CTCF. Altogether these results indicate that CTCF binding at BCL6 exon1A is associated with a transcriptionally active locus and protects the BCL6 regulatory region against repressive histone marks.

\section{DISCUSSION}

BCL6 is highly regulated during B cell differentiation such that naïve B-cells and terminally differentiated plasma cells do not express the protein whilst germinal centre B-cells express large amounts ${ }^{43}$. Repression of BCL6 is required for germinal centre exit once a high affinity antibody has been created and is essential for normal immunity. However, the mechanism by which the BCL6 locus is opened for transcription is not known but, by analogy with other loci, it may be that epigenetic marks are required prior to the recruitment of transcription factor complexes ${ }^{44,45}$.

In this report we analyse the BCL6 regulation by CTCF. We describe four novel findings: (i) CTCF binds to a previously undescribed site in BCL6 exon1A, associated with high level of BCL6 expression, (ii) silencing of CTCF is correlated with reduction of BCL6 expression in germinal centre B-cells and induction of BLIMP1 and other plasma cell markers, (iii) CTCF counteracted the negative autoregulation of BCL6 at exon1A, (iv) 
CTCF binding to BCL6 exon1A is not DNA methylation sensitive, but is associated with presence of active histone marks and protection against repressive marks.

The "CTCF binding sites database" constructed from CTCF binding sites identified by genome-wide screens, has been widely used to estimate the probability of CTCF binding to putative sites ${ }^{38,39}$. Using this tool we identified a new CTCF binding site in BCL6 exon1A. ENCODE ChIP-seq data confirmed CTCF binding site within BCL6 exon1A, together with H2A.Z and the cohesin subunit Rad21, in lymphoblastoid cells but not in myeloid K562 cells (supplementary Figure S6).

The BCL6 exon1A CTCF site is close (250 bp) downstream of the major transcription start site in a region that contains a BCL6 negative autoregulatory region. CTCF binding to BCL6 exon1A was demonstrated in vitro and in vivo. CTCF binding to sequences within BCL6 intron 1 have been recently described in plasma cells ${ }^{17}$ and the same was found in myeloid cells (this work). In contrast with the CTCF binding to intronic sites in non-germinal centre cells, CTCF is preferentially bound to exon1A in germinal centre cells when BCL6 is highly expressed. This suggests that CTCF might be involved in the transcriptional up-regulation of BCL6 by preventing BCL6 negative autoregulation. Supporting this concept, CTCF silencing in two germinal centre BCL6 expressing cell lines led to a reproducible reduction in BCL6 mRNA and protein expression. In addition, reporter assays performed in BCL6 expressing cells and using the CTCF binding site in exon1A showed a consistent increase in transcriptional activity upon transfection with CTCF expression vectors and counteracted the negative autoregulation of BCL6. Lai et $\mathrm{al}^{17}$ found that silencing of CTCF in the BCL6 non-expressing plasma cell line $\mathrm{NCl}-\mathrm{H} 929$ induced BCL6 expression together with specific markers of germinal centre cells. However, this was not the case in myeloid K562 cells where BCL6 expression was not detected upon CTCF silencing (this work). Moreover, a significant enrichment of CTCF at the BCL6 first intron was observed in K562 cells while MutullI, a BCL6 non-expressing germinal centre 
cell line showed no enrichment of CTCF at that region. Collectively our results and those of Lai et al. ${ }^{17}$ suggest that CTCF binding to BCL6 intron 1 is associated with repressed chromatin in non-BCL6 expressing plasma cells whereas at the CTCF exon1A binding site that we describe here there is association with open chromatin in BCL6 expressing germinal centre derived cell lines (Figure 7).

CTCF has been shown to be essential for the epigenetic regulation of several genes $^{31}$. In many cases, CTCF binding to the DNA was methylation sensitive ${ }^{17,30,46-48}$. However, insensitivity from DNA methylation has also been demonstrated ${ }^{47,49,50}$. Recent genome-wide occupancy studies indicate that $41 \%$ of variable CTCF binding was correlated with differential DNA methylation ${ }^{22}$. Our EMSA analysis using in vitro methylated probes clearly showed that CTCF binding to the BCL6 exon1A is not sensitive to methylation, despite being at a CpG island. Moreover, no methylation was observed at that region in lymphoma cell lines from different origin and in patient samples having different levels of BCL6 expression, in agreement with previous studies in other cells and tissues $\left[\mathrm{see}^{51}\right.$ and references therein]. This result was not completely unexpected since islands found in the control regions of tissue specific genes, are not usually regulated through DNA methylation but by covalent histone modifications ${ }^{52}$.

We analysed the presence of active and repressive histone marks at the BCL6 exon1A region in different lymphoma cells. Our ChIP assays showed that the enrichment of $\mathrm{H} 3 \mathrm{~K} 4 \mathrm{me} 2$ and of $\mathrm{H} 3 \mathrm{Ac}$ observed in the BCL6 expressing germinal centre cell lines was higher than in cells which do not express BCL6. Along with these active chromatin marks we found a notable enrichment of CTCF in Ramos, together with the variant histone H2A.Z. We therefore hypothesized that CTCF might be responsible for protecting the BCL6 exon1A regulatory region against repressive histone modifications. Such a mechanism has been recently described for the CTCF regulation of the p53 promoter ${ }^{34}$. In addition, a similar mechanism related to the loss of repressive histone modifications has 
also been proposed for the activation of the cancer-promoting gene CLDN3 in ovarian cancer $^{53}$. Indeed, ChIP assays performed in a germinal centre BCL6 expressing cell line after silencing CTCF, showed a reduction of active histone marks together with strong increase of repressive histone marks. Speculatively, dismissal of CTCF from its exon1A binding site may be one of the early events switching off the BCL6 locus and allowing assembly of the repressive complex. Our data are in agreement with the model proposed by Ramachandrareddy et $\mathrm{al}^{51}$, which have shown a significant enrichment of $\mathrm{H} 3 \mathrm{~K} 4 \mathrm{me} 2$ and of $\mathrm{H} 3 \mathrm{Ac}$ in germinal centre B-cells at the BCL6 promoter region but not in non-

germinal centre B-cells and have suggested that regulation of BCL6 might depend on long distance interactions of the promoter with upstream regions, and that these interactions might depend on CTCF binding ${ }^{51}$.

Our results suggest that the BCL6 exon1A CTCF site regulates BCL6 expression through a mechanism that is different from that mediated by the intronic sites. It is therefore tempting to speculate that BCL6 expression might depend on the stage-specific CTCF recruitment to the different BCL6 binding sites during B lymphocyte development (Figure 7). CTCF binding to exon1A appears to be required to maintain BCL6 expression by protecting BCL6 exon1A from BCL6 auto-repression in germinal centre cells. On the contrary, CTCF binding to the intronic region is more likely to be necessary to prevent BCL6 expression in non-germinal centre cells. Future research will be directed to clarify such mechanisms, given the essential role of BCL6 regulation in lymphomagenesis.

\section{MATERIALS AND METHODS}

\section{Cell culture, transfections and viral infections}

Ramos, DG75, MutullI and Raji cells (from Burkitt's lymphoma), Toledo and Ly03 cells (from diffuse large B cell lymphoma), Bjab (B-cell lymphoma) and K562 cells (from chronic myeloid leukemia) were grown under standard conditions (see supplementary table S1). 
FISH analysis ruled out BCL6 rearrangements in the studied cell lines (supplementary Figure S3).

DG75 and K562 cells were transfected using a nucleofector (Amaxa, Germany) with $2 \mu \mathrm{g}$ to $10 \mu \mathrm{g}$ of expression vectors and $0.5 \mu \mathrm{g}$ of a green fluorescent protein vector (pmaxGFP, Amaxa) to assess transfection efficiency. HEK293T cells were transfected with $5 \mu \mathrm{g}$ of pEGFP-CTCF-full length, pEGFP-CTCF-Nt or pCDNA-CTCF expression vectors using jetPEI (Genycell Biotech). Cells were harvested $48 \mathrm{~h}$ after transfection and nuclear extracts were used for EMSA analysis. For CTCF silencing, pRS-CTCF retroviral vector was constructed by inserting the siRNA sequence described in ref. ${ }^{54}$, into the pRetroSuper vector $(\mathrm{pRS})^{55}$. Viral stocks were generated essentially as described ${ }^{55}$. Lymphoma derived cells were either nucleofected or transduced with pRS and pRS-CTCF and harvested 48 to 96 hours after infection. CTCF expression was analyzed by RT-qPCR and western-blot.

\section{Purification of primary lymphoma cells}

Lymph nodes biopsies of patients with lymphomas were provided by the Haematology Department of the Hospital Universitario Marqués de Valdecilla with informed consent and approval from the local ethics committee (CEIC, ref. 13/2011) granted by the Ethics Committee on Clinical Research of Cantabria, Spain. Single cell suspensions from the lymph node were separated by the FACSAria (BD Biosciences) using the FCS/SSC parameters and one to three specific monoclonal antibodies against surface markers specific of each type of lymphoid neoplasm using standard protocols.

\section{RNA analysis by reverse transcription and PCR (RTqPCR)}

Total RNA was isolated by using the RNeasy kit (Qiagen). For reverse transcription firststrand cDNA was synthesized from $2 \mu \mathrm{g}$ of total RNA by using SuperScript II RNase reverse transcriptase (Invitrogen) with random primers. Quantitative PCR was performed 
with a QuantiTect Sybr green PCR kit (Qiagen). The data of BCL6 and CTCF mRNA expression were normalized to ribosomal protein S14 mRNA levels (primers shown in supplementary table S2). Results were analyzed by comparative $\Delta \Delta \mathrm{Ct}$ method and expressed as mean \pm SEM of duplicate PCRs from at least two independent experiments.

\section{Western blot analysis.}

Cells were lysed in RIPA lysis buffer and immunoblots were performed as previously described $^{16}$. Antibodies used were: anti-CTCF monoclonal antibody (612149) from BD Biosciences, anti-BCL6 polyclonal antibody (N-3; sc-858) and anti-actin (I-19; sc-1616) both from Santa Cruz Biotech. Blots were developed with secondary antibodies conjugated to IRDye680 or IRDye800 (Li-Cor Biosciences) and visualized with an Odyssey infrared-imaging system (Li-Cor Biosciences).

\section{Luciferase Reporter Assays}

The BCL6(-4.9/+0.5)-pGL3 construct was generated by inserting a BCL6 regulatory region including the CTCF site into pGL3 basic as previously described ${ }^{15}$. The pCDNA-BCL6 expression vector was generated by subcloning the full-length BCL6 cDNA into the pcDNA3.1+ vector (Invitrogen). Appropriate sequences and expression were verified by sequencing and western-blot. CTCF expression vectors used were: CDNA-CTCF $^{56}$ and three different pEGFP-CTCF constructs (pEGFP-CTCF-full length, pEGFP-CTCF-Zinc finger, pEGFP-CTCF-C terminal) ${ }^{57}$.

For luciferase assays in DG75 lymphoma cells, $4 \mu \mathrm{g}$ of the pGL3 basic vector (Promega) or equimolar concentrations of the BCL6(-4.9/+0.5)-pGL3 reporter vector, were cotransfected together with $7 \mu \mathrm{g}$ of the CTCF expression vectors and $0.6 \mu \mathrm{g}$ of the pRL null vector (Promega) into ten million DG75 cells by nucleofection. Luciferase assays in HEK293T were performed essentially as described ${ }^{8}$. Cells were transfected with jetPEI 
using 0.1 pmol of reporter vectors (pGL3 basic or BCL6(-4.9/+0.5)-pGL3) and 0.1 pmol of $\mathrm{pRL}$ null, together with increasing amounts $(0.01,0.05,0.1,0.5 \mathrm{pmol})$ of the pCDNA-BCL6 vector or were cotransfected with 0.05 pmol of pCDNA-BCL6 and increasing amounts $(0.12,0.24,0.48,0.96 \mathrm{pmol})$ of the pCDNA-CTCF vector. The total amount of transfected DNA was kept constant in each experiment by adding pCDNA vector. Luciferase activities were measured 48 hours after transfection using the Dual-Glo Luciferase Reporter System (Promega) in a Luminometer TD 20/20 Turner Designs. For each determination, luciferase activity was calculated as the Firefly activity normalized by the Renilla activity. Luciferase activity in arbitrary units (a.u.) was shown as the increase in activation relative to the activity of the pGL3 vector alone (value one).

\section{Electrophoretic mobility shift assay (EMSA)}

A 198 bp radioactive labelled probe, including the CTCF binding site at BCL6 exon1A, was obtained by PCR from genomic DNA (primers shown in supplementary table S2). In addition, a IRDye labelled double-stranded oligonucleotide of $80 \mathrm{nt}$ (sequence shown in supplementary Figure S1) was used as a probe. Nuclear extracts were obtained from transfected HEK293T cells and EMSAs were performed essentially as previously described $^{30}$. For supershift experiments, $1 \mu$ of anti-CTCF mouse monoclonal (BD Biosciences) or anti-actin (used as non-specific antibody) was added to the binding reaction before the labeled probe. For EMSA with methylated probes, purified BCL6 fragments were methylated in vitro using SssI CpG methyltransferase (New England Biolabs) and S-adenosyl-L-methionine ${ }^{30}$. Control and methylated probes were digested with CpG methylation sensitive enzymes to assess the level of methylation. 


\section{Bisulfite Genomic Sequencing}

DNA was obtained from lymphoma cell lines and samples from lymphoma patients using the DNeasy Blood \& Tissue Kit (Qiagen). Bisulfite conversion was performed using the commercial kit EZ DNA Methylation-Gold Kit Zymo Research. BSP primers were designed using the Methyl Primer Express software (Applied Biosystems) (supplementary table S2). Five $\mu$ l of the bisulfite modified DNA was amplified using the Expand High Fidelity PCR System (Roche). The PCR products were cloned into the pGEM-T easy vector (Promega) and independent clones for each sample were sequenced. For control of DNA methylation, Universal Methylated Human DNA Standard was used (ZYMO research corp).

\section{Chromatin ImmunoPrecipitation (ChIP)}

ChIP assays were performed using a modified version of the Upstate Biotechnology protocol as described previously ${ }^{58}$. Cells were fixed in formaldehyde, lysed and sonicated using a Bioruptor UCD-200TM (Diagenode). ChIP was performed using Dynabeadsprotein G (Invitrogen) coupled to different antibodies: polyclonal anti-CTCF-Ab-1 (07-729) from Millipore; anti-CTCF-Ab2, a mixture of 9 different monoclonal antibodies ${ }^{59}$; antiH3K9me3 (ab8898), anti-H3K4me2 (ab32356) and anti-H2A.Z (ab4174) from Abcam; antiH3acetylated (06-599) and H3K27me3 (07-449) from Millipore. Real-time PCR of immunoprecipitated DNA was performed in duplicate with equal amounts of specific antibody immunoprecipitated sample, control (beads) and input. Primers used for ChIP assays are shown in supplementary table S2. The comparative cycle threshold approach was used for the data analysis as described ${ }^{48}$. The signals were normalized to the inputs and the fold enrichment was calculated relative to the control sample (no-antibody). The values are the mean \pm S.E.M. of two to six independent experiments. Normalization of histone marks was based on the ChIP-IT qPCR analysis kit (Active motif North America). 


\section{CONFLICT OF INTEREST}

The authors declare no conflict of interest.

\section{ACKNOWLEDGEMENTS}

We thank Elena Klenova and Rainer Renkawitz for CTCF expression vectors, Miguel Angel Piris and Noemi Nagy for cell lines and Javier León for useful comments on the manuscript. The authors are grateful to the Department of Hematology of Hospital $U$. Marques de Valdecilla (Santander) for help with patient recruitment. Funding for this work was provided by Instituto de Salud Carlos III grants PI11/00397 (Fondo Investigaciones Sanitarias) and RETIC (Red Tematica de Investigacion Cooperativa en Cancer) RD06/0020/0017 and RD12/0036/0033. A.B was supported by a López Albo fellowship (IFIMAV, Spain). Part of and this work is in A.B. PhD dissertation (split PhD Programme between Imperial College London and the University of Cantabria), MRG by a PhD fellowship from the University of Cantabria and V.T. by the Lady Tata Memorial Trust.

Supplementary Information accompanies the paper on the Oncogene website (http://www.nature.com./onc) 


\section{REFERENCES}

1 Ye BH, Cattoretti G, Shen Q, Zhang J, Hawe N, de Waard R et al. The BCL-6 proto-oncogene controls germinal-centre formation and Th2-type inflammation. Nat Genet 1997; 16: 161-170.

2 Basso K, Dalla-Favera R. Roles of BCL6 in normal and transformed germinal center B cells. Immunological reviews 2012; 247: 172-183.

3 Fearon DT, Manders PM, Wagner SD. Bcl-6 uncouples B lymphocyte proliferation from differentiation. Advances in experimental medicine and biology 2002; 512: 21-28.

4 Reljic R, Wagner SD, Peakman LJ, Fearon DT. Suppression of signal transducer and activator of transcription 3-dependent B lymphocyte terminal differentiation by BCL-6. The Journal of experimental medicine 2000; 192: 1841-1848.

5 Basso K, Dalla-Favera R. BCL6: master regulator of the germinal center reaction and key oncogene in B cell lymphomagenesis. Adv Immunol 2010; 105: 193210.

6 Wagner SD, Ahearne M, Ko Ferrigno P. The role of BCL6 in lymphomas and routes to therapy. Br J Haematol 2011; 152: 3-12.

7 Cattoretti G, Pasqualucci L, Ballon G, Tam W, Nandula SV, Shen Q et al. Deregulated BCL6 expression recapitulates the pathogenesis of human diffuse large B cell lymphomas in mice. Cancer Cell 2005; 7: 445-455.

8 Pasqualucci L, Migliazza A, Basso K, Houldsworth J, Chaganti RS, Dalla-Favera R. Mutations of the BCL6 proto-oncogene disrupt its negative autoregulation in diffuse large B-cell lymphoma. Blood 2003; 101: 2914-2923.

9 Wang X, Li Z, Naganuma A, Ye BH. Negative autoregulation of BCL-6 is bypassed by genetic alterations in diffuse large B cell lymphomas. Proceedings of the National Academy of Sciences of the United States of America 2002; 99: 15018-15023.

10 Scheeren FA, Naspetti M, Diehl S, Schotte R, Nagasawa M, Wijnands E et al. STAT5 regulates the self-renewal capacity and differentiation of human memory B cells and controls Bcl-6 expression. Nat Immunol 2005; 6: 303-313.

11 Saito M, Gao J, Basso K, Kitagawa Y, Smith PM, Bhagat G et al. A signaling pathway mediating downregulation of BCL6 in germinal center B cells is blocked by BCL6 gene alterations in B cell lymphoma. Cancer Cell 2007; 12: 280-292.

12 Duan S, Cermak L, Pagan JK, Rossi M, Martinengo C, di Celle PF et al. FBX011 targets BCL6 for degradation and is inactivated in diffuse large B-cell lymphomas. Nature 2012; 481: 90-93.

13 Niu H, Ye BH, Dalla-Favera Rk. Antigen receptor signaling induces MAP kinasemediated phosphorylation and degradation of the BCL-6 transcription factor. Genes \& development 1998; 12: 1953-1961. 
14 Bereshchenko OR, Gu W, Dalla-Favera R. Acetylation inactivates the transcriptional repressor BCL6. Nat Genet 2002; 32: 606-613.

15 Papadopoulou V, Postigo A, Sanchez-Tillo E, Porter AC, Wagner SD. ZEB1 and CtBP form a repressive complex at a distal promoter element of the BCL6 locus. The Biochemical journal 2010; 427: 541-550.

16 Batlle A, Papadopoulou V, Gomes AR, Willimott S, Melo JV, Naresh K et al. CD40 and B-cell receptor signalling induce MAPK family members that can either induce or repress Bcl-6 expression. Molecular immunology 2009; 46: 17271735.

17 Lai AY, Fatemi M, Dhasarathy A, Malone C, Sobol SE, Geigerman C et al. DNA methylation prevents CTCF-mediated silencing of the oncogene BCL6 in B cell lymphomas. The Journal of experimental medicine 2010; 207: 1939-1950.

18 Ohlsson R, Lobanenkov V, Klenova E. Does CTCF mediate between nuclear organization and gene expression? Bioessays 2010; 32: 37-50.

19 Phillips JE, Corces VG. CTCF: master weaver of the genome. Cell 2009; 137: 1194-1211.

20 Kim TH, Abdullaev ZK, Smith AD, Ching KA, Loukinov DI, Green RD et al. Analysis of the vertebrate insulator protein CTCF-binding sites in the human genome. Cell 2007; 128: 1231-1245.

21 Chen X, Xu H, Yuan P, Fang F, Huss M, Vega VB et al. Integration of external signaling pathways with the core transcriptional network in embryonic stem cells. Cell 2008; 133: 1106-1117.

22 Wang H, Maurano MT, Qu H, Varley KE, Gertz J, Pauli F et al. Widespread plasticity in CTCF occupancy linked to DNA methylation. Genome Res 2012; 22: 1680-1688.

23 Lee BK, Bhinge AA, Battenhouse A, McDaniell RM, Liu Z, Song L et al. Cell-type specific and combinatorial usage of diverse transcription factors revealed by genome-wide binding studies in multiple human cells. Genome Res 2012; 22: 924.

24 Herold M, Bartkuhn M, Renkawitz R. CTCF: insights into insulator function during development. Development (Cambridge, England) 2012; 139: 10451057.

25 Barski A, Cuddapah S, Cui K, Roh TY, Schones DE, Wang Z et al. High-resolution profiling of histone methylations in the human genome. Cell 2007; 129: 823837.

26 Cuddapah S, Jothi R, Schones DE, Roh TY, Cui K, Zhao K. Global analysis of the insulator binding protein CTCF in chromatin barrier regions reveals demarcation of active and repressive domains. Genome Res 2009; 19: 24-32.

27 Parelho V, Hadjur S, Spivakov M, Leleu M, Sauer S, Gregson HC et al. Cohesins functionally associate with CTCF on mammalian chromosome arms. Cell 2008; 132: 422-433.

28 Wendt KS, Yoshida K, Itoh T, Bando M, Koch B, Schirghuber E et al. Cohesin mediates transcriptional insulation by CCCTC-binding factor. Nature 2008; 451: 796-801. 
29 Yusufzai TM, Tagami H, Nakatani Y, Felsenfeld G. CTCF tethers an insulator to subnuclear sites, suggesting shared insulator mechanisms across species. Molecular cell 2004; 13: 291-298.

30 van de Nobelen S, Rosa-Garrido M, Leers J, Heath $\mathrm{H}$, Soochit W, Joosen L et al. CTCF regulates the local epigenetic state of ribosomal DNA repeats. Epigenetics \& chromatin 2010; 3: 19.

31 Filippova GN. Genetics and epigenetics of the multifunctional protein CTCF. Curr Top Dev Biol 2008; 80: 337-360.

32 Klenova EM, Nicolas RH, Paterson HF, Carne AF, Heath CM, Goodwin GH et al. CTCF, a conserved nuclear factor required for optimal transcriptional activity of the chicken c-myc gene, is an 11-Zn-finger protein differentially expressed in multiple forms. Molecular and cellular biology 1993; 13: 7612-7624.

33 De La Rosa-Velazquez IA, Rincon-Arano H, Benitez-Bribiesca L, Recillas-Targa F. Epigenetic regulation of the human retinoblastoma tumor suppressor gene promoter by CTCF. Cancer research 2007; 67: 2577-2585.

34 Soto-Reyes E, Recillas-Targa F. Epigenetic regulation of the human p53 gene promoter by the CTCF transcription factor in transformed cell lines. Oncogene 2010; 29: 2217-2227.

35 Witcher M, Emerson BM. Epigenetic silencing of the p16(INK4a) tumor suppressor is associated with loss of CTCF binding and a chromatin boundary. Molecular cell 2009; 34: 271-284.

36 Renaud S, Loukinov D, Bosman FT, Lobanenkov V, Benhattar J. CTCF binds the proximal exonic region of hTERT and inhibits its transcription. Nucleic acids research 2005; 33: 6850-6860.

37 Bernardin F, Collyn-d'Hooghe M, Quief S, Bastard C, Leprince D, Kerckaert JP. Small deletions occur in highly conserved regions of the LAZ3/BCL6 major translocation cluster in one case of non-Hodgkin's lymphoma without 3q27 translocation. Oncogene 1997; 14: 849-855.

38 Bao L, Zhou M, Cui Y. CTCFBSDB: a CTCF-binding site database for characterization of vertebrate genomic insulators. Nucleic acids research 2008; 36: D83-87.

39 Ziebarth JD, Bhattacharya A, Cui Y. CTCFBSDB 2.0: a database for CTCF-binding sites and genome organization. Nucleic acids research 2013; 41: D188-194.

40 Kikuchi M, Miki T, Kumagai T, Fukuda T, Kamiyama R, Miyasaka N et al. Identification of negative regulatory regions within the first exon and intron of the BCL6 gene. Oncogene 2000; 19: 4941-4945.

41 Kouzarides T. Chromatin modifications and their function. Cell 2007; 128: 693705.

42 Sharma S, Kelly TK, Jones PA. Epigenetics in cancer. Carcinogenesis 2010; 31: 27-36.

43 Cattoretti G, Chang CC, Cechova K, Zhang J, Ye BH, Falini B et al. BCL-6 protein is expressed in germinal-center B cells. Blood 1995; 86: 45-53.

44 Bottardi S, Aumont A, Grosveld F, Milot E. Developmental stage-specific epigenetic control of human beta-globin gene expression is potentiated in hematopoietic progenitor cells prior to their transcriptional activation. Blood 2003; 102: 3989-3997. 
45 Szutorisz H, Canzonetta C, Georgiou A, Chow CM, Tora L, Dillon N. Formation of an active tissue-specific chromatin domain initiated by epigenetic marking at the embryonic stem cell stage. Molecular and cellular biology 2005; 25: 18041820.

46 Yoon B, Herman H, Hu B, Park YJ, Lindroth A, Bell A et al. Rasgrf1 imprinting is regulated by a CTCF-dependent methylation-sensitive enhancer blocker. Molecular and cellular biology 2005; 25: 11184-11190.

47 Renaud S, Pugacheva EM, Delgado MD, Braunschweig R, Abdullaev Z, Loukinov $\mathrm{D}$ et al. Expression of the CTCF-paralogous cancer-testis gene, brother of the regulator of imprinted sites (BORIS), is regulated by three alternative promoters modulated by CpG methylation and by CTCF and p53 transcription factors. Nucleic acids research 2007; 35: 7372-7388.

48 Fitzpatrick GV, Pugacheva EM, Shin JY, Abdullaev Z, Yang Y, Khatod K et al. Allele-specific binding of CTCF to the multipartite imprinting control region KvDMR1. Molecular and cellular biology 2007; 27: 2636-2647.

49 Vatolin S, Abdullaev Z, Pack SD, Flanagan PT, Custer M, Loukinov DI et al. Conditional expression of the CTCF-paralogous transcriptional factor BORIS in normal cells results in demethylation and derepression of MAGE-A1 and reactivation of other cancer-testis genes. Cancer research 2005; 65: 7751-7762.

50 Hong JA, Kang Y, Abdullaev Z, Flanagan PT, Pack SD, Fischette MR et al. Reciprocal binding of CTCF and BORIS to the NY-ESO-1 promoter coincides with derepression of this cancer-testis gene in lung cancer cells. Cancer research 2005; 65: 7763-7774.

51 Ramachandrareddy H, Bouska A, Shen Y, Ji M, Rizzino A, Chan WC et al. BCL6 promoter interacts with far upstream sequences with greatly enhanced activating histone modifications in germinal center B cells. Proceedings of the National Academy of Sciences of the United States of America 2010; 107: 1193011935.

52 Weber M, Hellmann I, Stadler MB, Ramos L, Paabo S, Rebhan M et al. Distribution, silencing potential and evolutionary impact of promoter DNA methylation in the human genome. Nat Genet 2007; 39: 457-466.

53 Kwon MJ, Kim SS, Choi YL, Jung HS, Balch C, Kim SH et al. Derepression of CLDN3 and CLDN4 during ovarian tumorigenesis is associated with loss of repressive histone modifications. Carcinogenesis 2010; 31: 974-983.

54 Ishihara K, Oshimura M, Nakao M. CTCF-dependent chromatin insulator is linked to epigenetic remodeling. Molecular cell 2006; 23: 733-742.

55 Brummelkamp TR, Bernards R, Agami R. Stable suppression of tumorigenicity by virus-mediated RNA interference. Cancer Cell 2002; 2: 243-247.

56 Torrano V, Chernukhin I, Docquier F, D'Arcy V, Leon J, Klenova E et al. CTCF regulates growth and erythroid differentiation of human myeloid leukemia cells. The Journal of biological chemistry 2005; 280: 28152-28161.

57 Torrano V, Navascues J, Docquier F, Zhang R, Burke LJ, Chernukhin I et al. Targeting of CTCF to the nucleolus inhibits nucleolar transcription through a poly(ADP-ribosyl)ation-dependent mechanism. Journal of cell science 2006; 119: $1746-1759$. 
58 Rosa-Garrido M, Ceballos L, Alonso-Lecue P, Abraira C, Delgado MD, Gandarillas A. A cell cycle role for the epigenetic factor CTCF-L/BORIS. PloS one 2012; 7: e39371.

59 Pugacheva EM, Tiwari VK, Abdullaev Z, Vostrov AA, Flanagan PT, Quitschke WW et al. Familial cases of point mutations in the XIST promoter reveal a correlation between CTCF binding and pre-emptive choices of X chromosome inactivation. Human molecular genetics 2005; 14: 953-965. 


\section{FIGURE LEGENDS}

Figure 1. CTCF binds in vitro to a predicted site at the BCL6 exon1A regulatory region. (a) Scheme of a BCL6 gene region spanning from the -2960 to $+4970 \mathrm{bp}$. The transcription start site is indicted as +1 (ref. ${ }^{37}$ ). Seven amplicons used for ChIP analysis are indicated. Amplicons (6) and (7) correspond to the intronic CTCF binding sites previously identified ${ }^{17}$. Amplicon (5) corresponds to a novel CTCF binding site on BCL6 exon1A predicted by the four motifs of the "CTCF binding site database" 38 with high score (average: 12.75). The BCL6 exon1A sequence shows the CTCF binding site, BCL6 autoregulatory binding sites (BCL6-BSE1A and BCL6-BSE1B) $\left(\right.$ ref $^{8}$ ) and the primers used for the EMSA (underlined). CpG di-nucleotides are indicated in bold. (b) EMSA to analyze in vitro binding of CTCF to BCL6 exon1A. Probes were ${ }^{32} \mathrm{P}$ labelled PCR fragments of MYC-N, a known CTCF binding site used as positive control (left panel), and of BCL6 exon1A (right panel) (primer sequences shown in supplementary table S2). Nuclear extracts were obtained from mock transfected 293T cells or from 293T transfected either with pEGFP-CTCF full length (293T-CTCF) or pEGFP-CTCF-N-terminal (293T-CTCF-Nt) expression vectors. CTCF was overexpressed to increase the levels of the protein in the extracts to better distinguish between the CTCF-DNA complexes and the unspecific bands. The CTCF shifted bands are shown by an arrow. For supershift experiments, an anti-CTCF monoclonal antibody was added (asterisk, supershifted band). The specificity of the supershift was assessed with an anti-actin antibody.

Figure 2. CTCF interacts in vivo with BCL6 exon1A regulatory region. (a) ChIP assays to analyze CTCF in vivo binding to BCL6 exon1A. Chromatin from Ramos lymphoma cells was immunoprecipitated with two different anti-CTCF antibodies, a rabbit polyclonal antibody ( $\alpha$ CTCF-Ab1) and a mixture of 9 monoclonal antibodies ( $\alpha$ CTCF- 
$A b 2)^{59}$, and subjected to quantitative PCR for the CTCF binding site within BCL6 exon1A. The H42.1 rDNA CTCF binding site and the MYC-H.1 were used as positive and negative controls, respectively ${ }^{30}$. The fold enrichment for a particular target sequence was determined by calculating the ratio of the amount of the target sequence in the immunoprecipitation over the amount of the target sequence in the input DNA, using the following formula: $2\left({ }^{\mathrm{CT}}\right.$ Input- CT immunoprecipitated sample $)$ where CT is the number of cycles needed to raise the threshold. Each value was normalized with respect to the control (noantibody). Right panels show typical PCR products after the ChIP analysis. (b) ChIP to analyse enrichment of histone variant H2A.Z at BCL6 exon1A in Ramos cells. (c) ChIP assays performed in Ramos cells as indicated in (a), to analyze in vivo binding of CTCF to the BCL6 regulatory region spanning from the -2960 to $+4970 \mathrm{bp}$. The location of amplicons (1) to (7) is shown in the scheme of Figure 1a. (d) ChIP examining the relative CTCF fold enrichment at the indicated amplicons. Chromatin from Ramos (high BCL6 expression), Mutulll and K562 cells (undetectable BCL6 expression) was immunoprecipitated with anti CTCF-Ab1 polyclonal antibody.

Figure 3. Silencing of CTCF decreased BCL6 expression and induced plasma cell markers. (a) RT-qPCR showing silencing of CTCF and decreased BCL6 mRNA expression. DG75 cells were nucleofected with a short hairpin RNA vector for CTCF (pRSCTCF) or the empty vector (pRS). CTCF (left panel) and BCL6 (right panel) relative mRNA expression were analyzed at the indicated times after transfection. (b) Western blot showing CTCF and BCL6 protein expression in DG75 cells nucleofected as above. Actin was used as loading control. (c-d) Similar results were obtained in Ramos cells infected with pRS or pRS-CTCF retroviruses. CTCF and BCL6 expression were analysed by RTqPCR (c) and western blot (d). (e) RT-qPCR showing silencing of CTCF and undetectable BCL6 mRNA expression in myeloid K562 cells. Positive control, Ramos cells. (f) Western 
blot showing CTCF and BCL6 protein expression on K562 cells nucleofected as in (a). Arrow indicates BCL6 protein as shown by the BCL6 positive control (Ramos cell lysate). The upper band (asterisk) in the K562 panel is a non-specific band. Actin was used as loading control. (g) RT-qPCR showing silencing of CTCF and upregulation of CCND2 (left panel), BLIMP1 (middle panel) and IRF4 (right panel) mRNA expression. DG75 cells were nucleofected with a short hairpin RNA vector for CTCF (pRS-CTCF) or the empty vector (pRS) and relative mRNA expression was analyzed as in (a).

Figure 4. Luciferase assays showing the effects of CTCF ectopic expression on BCL6 promoter activity. (a) DG75 cells were transiently co-transfected with either pGL3 vector or with the BCL6(-4.9/+0.5)-pGL3 reporter vector, together with the indicated CTCF expression vectors. pRL-null vector was used to normalize for transfection efficiency. The data show the means \pm S.D. of three measurements in two independent experiments.

(b) HEK293T cells were transiently co-transfected with either pGL3 vector or with the BCL6(-4.9/+0.5)-pGL3 reporter vector together with the indicated amounts of BCL6 and CTCF expression vectors. pRL-null vector was used to normalize for transfection efficiency. The data show the means \pm S.D. of three measurements in two independent experiments. a.u., arbitrary units

Figure 5. CTCF binds BCL6 exon1A in a methylation insensitive manner. (a) Assessment of complete methylation of the Sssl treated probe. Probes were ${ }^{32} \mathrm{P}$ labelled PCR fragments of BCL6 exon1A. Control and Sssl treated methylated probes were uncut or digested with the indicated restriction enzymes and run on an $8 \%$ polyacrilamide gel. (b) EMSA experiment using control and methylated BCL6 exon1A probes as indicated. Nuclear extracts were obtained from 293T cells mock transfected or transfected with the expression vector pEGFP-CTCF (293T-CTCF). The CTCF shifted bands are shown by an 
arrow. Unlabelled (cold) probe was used as a competitor. For supershift experiments (asterisk, supershifted band) an anti-CTCF monoclonal antibody was added. The specificity of the supershift was assessed with an anti-actin antibody. (c) Methylation status of BCL6 exon1A regulatory region. A scheme of BCL6 gene including the CTCF binding site on the exon1A is shown. DNA methylation status was investigated by sequencing of bisulfite-modified genomic DNA of three cell lines with undetectable expression of BCL6 protein (K562, Mutulll and Toledo), of three BCL6 expressing cell lines (Ly03, Ramos and DG75) and of several patients with different types of lymphomas: two diffuse large B cell lymphoma patient (DLBCL), two follicular lymphoma ( $F L)$, one mantle lymphoma $(\mathrm{ML})$, one Burkitt lymphoma $(\mathrm{BL})$ and one acute lymphoblastic leukemia (ALL). Unmethylated CpG dinucleotides are indicated as open circles. Between five to ten independent clones were sequenced. Positive control for the bisulfite transformation assay and the ability to detect methylation was carried out (supplementary Figure S4).

Figure 6. Presence of histone marks at BCL6 exon1A and effects of CTCF silencing on the local chromatin structure. (a) ChIP assay to analyse the relative enrichment of active (H3Ac, H3K4me2) and repressive (H3K9me3 and $\mathrm{H} 3 \mathrm{~K} 27 \mathrm{me} 3)$ histone marks at the BCL6 exon1A. Chromatin was prepared from Ramos and Mutulll lymphoma cells. Bottom panel shows typical PCR products after the ChIP analysis. Histone open chromatin marks were normalized against genomic sites enriched in repressive histone marks and vice versa (see supplementary Figure S5) (b) CTCF knockdown induced incorporation of repressive histone marks within BCL6 exon1A region. ChIP assays were performed in Ramos cells infected with pRS or pRS-CTCF retrovirus. Chromatin was immunoprecipitated with the indicated antibodies. Bottom panel shows typical PCR products after the ChIP analysis. 
Figure 7. Model for BCL6 regulation by CTCF. BCL6 is required to differentiate follicular B cells into germinal centre B cells and to maintain these cells in this state. In order to allow sustained BCL6 expression in those cells, inhibition of BCL6 exon 1 negative autoregulatory circuit is accomplish by CTCF binding to exon1A (this work). In contrast, methylation of BCL6 intron 1 avoids CTCF occupancy at that region in germinal centre cells, allowing BCL6 transcription (Lai et $\mathrm{al}^{17}$ ). Once $\mathrm{B}$ cells have completed the high affinity maturation process can differentiate into plasmatic cells. For this to happen, CTCF is released from exon1A site allowing BCL6 negative autoregulatory circuit to function. Also, demethylation of BCL6 intron 1 leads to CTCF binding to intron 1 which has been shown to represses BCL6 transcription. Binding of BCL6 to its negative autoregulatory sites and absence of CTCF occupancy at exon1A leads to the recruitment of repressive histone marks like $\mathrm{H} 3 \mathrm{~K} 9$ me3 or H3K27me3 (this work), given rise to chromatin condensation and inhibition of BCL6 expression. BCL6 downregulation induces upregulation of BLIMP1 and IRF4, which are both required for plasma cell differentiation. 


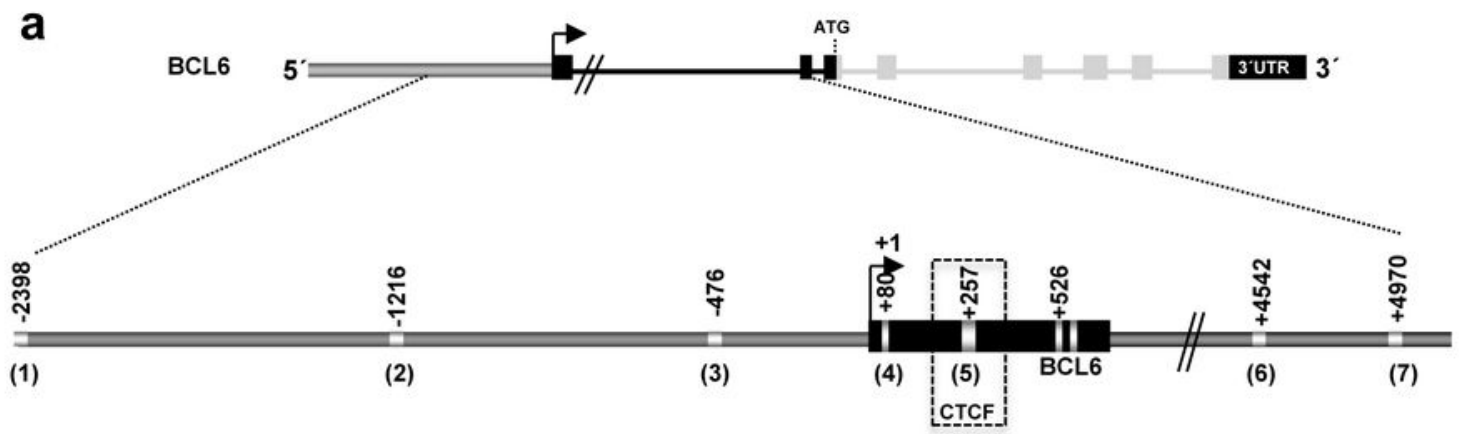

$\underset{+1}{\longrightarrow} \underset{+1}{\longrightarrow}$ CAGTGGTTCAAACCTCTCGCTCCCTTTTGTGCATTTAGCTCGATCTGCTGAGTTTATGGGTAAGAAAGAAGGAATTAGCCCCAGACCCCGG GAAAGCAAAGCGCACTCCCCCTCTTATGTCACCGAATAGCAAATTAGTTCTCAGAATTCCAGAGGCCGAGCTTTGCTACAGCGAAGGCGCCGAC GTCACAGAGGAGGAGCCCACGTGATGGTGGCGGAGCAGGCCATACCATCGTCTTGGGCCCGGGGAGGGAGAGCCACCTTCAGGCCCCTCGA GCCTCGAACCGGAACCTCCAAATCCGAGACGCTCTGCTTATGAGGACCTCGAAATATGCCGGCCAGTGAAAAATCTTGTGGCTTTGAGGGCTT TTGGTTGGCCAGGGGCAGTAAAAATCTCGGAGAGCTGACACCAAGTCCTCCCCTGCCACGTAGCAGTGGTAAAGTCCGAAGCTCAAATTCCGAG AATTGAGCTCTGTTGATTCTTAGAACTGGGGTCTTAGAATGGTGATGCAAGAAGTTCTAGGAAAGGCC BCL6-BSE1A BCL6-BSE1B

b

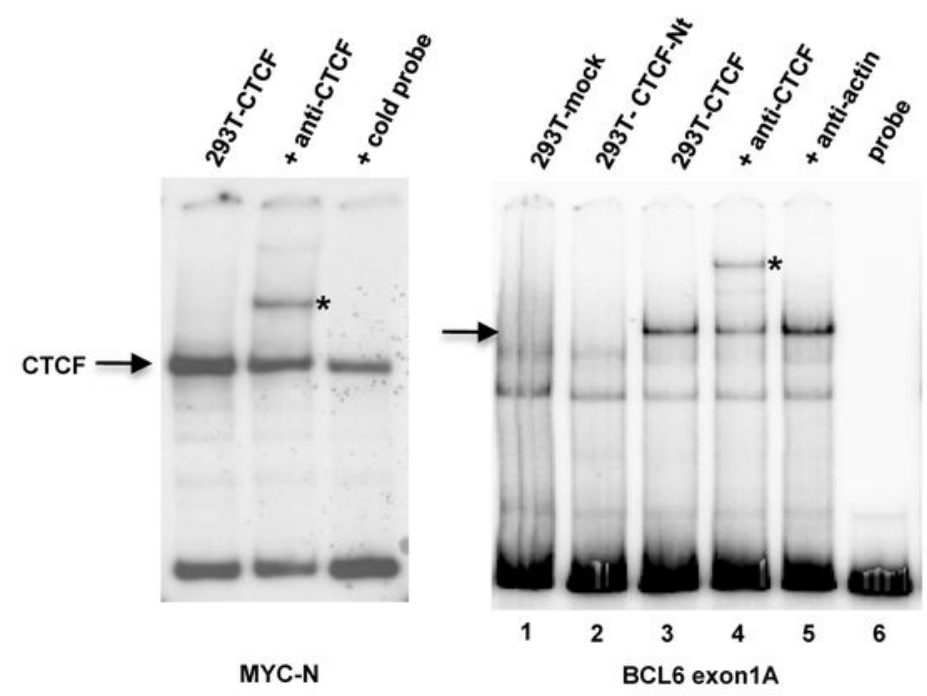


Figure 2

Batlle-López, A. et al

a

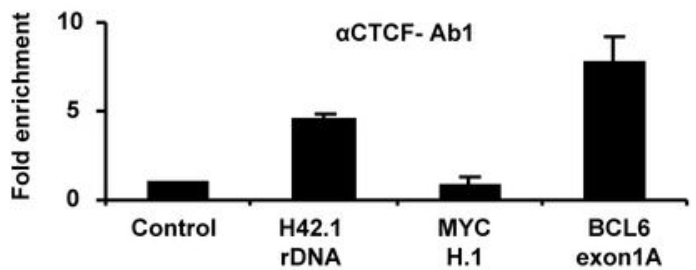

BCL6 exon1A
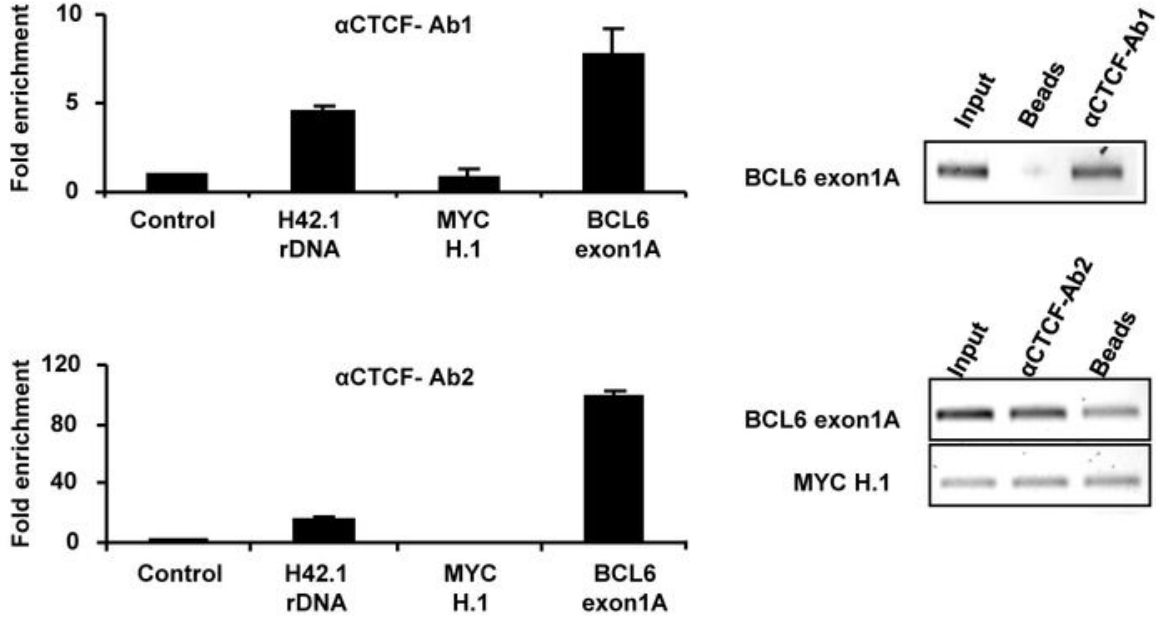

b

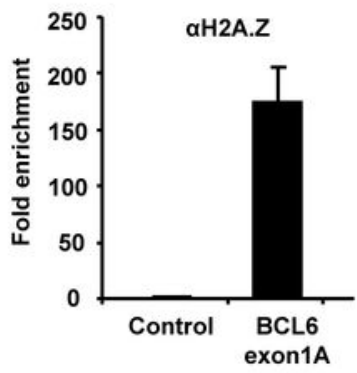

d

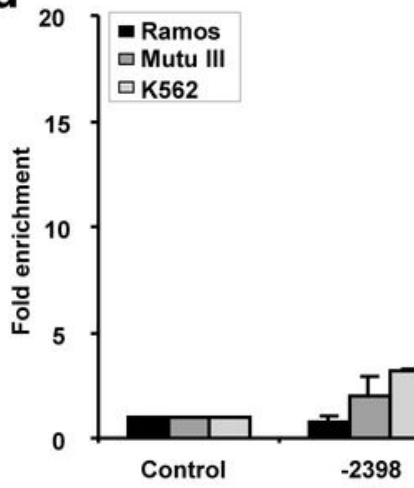

(1)
C

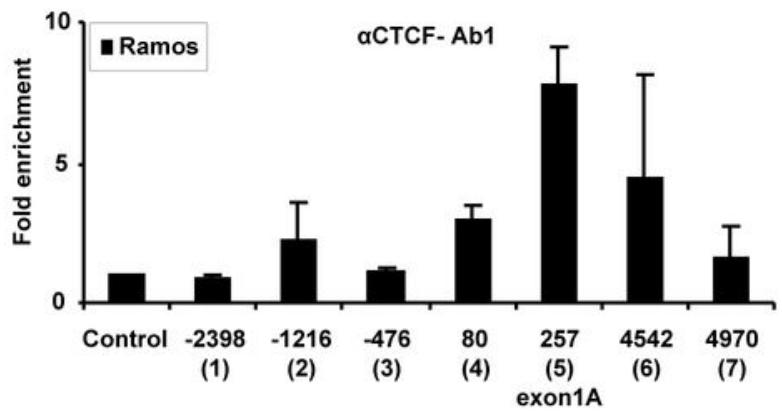


a

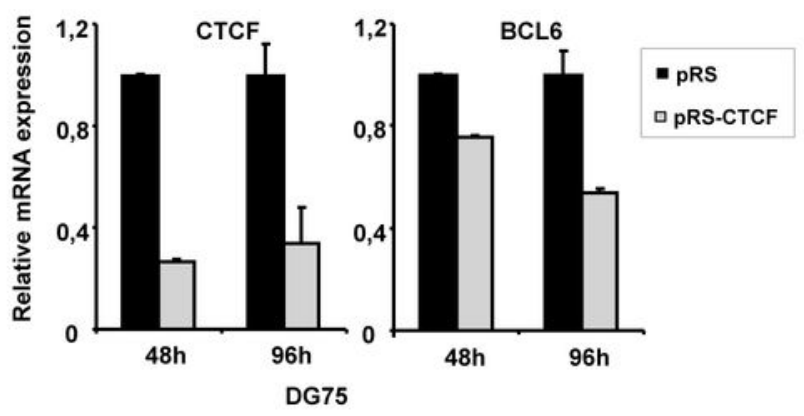

C

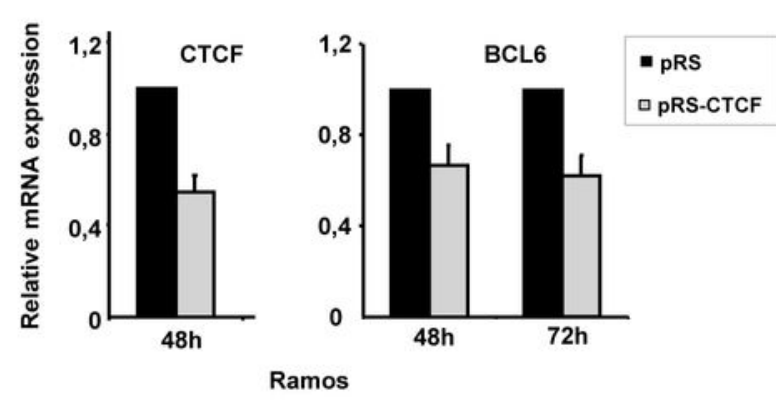

e

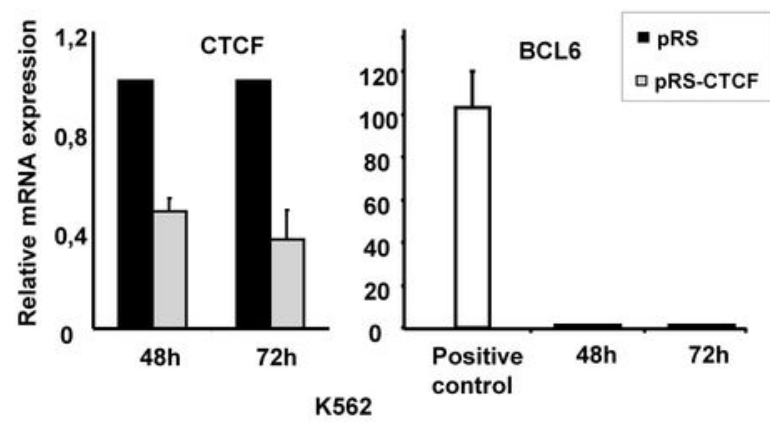

b

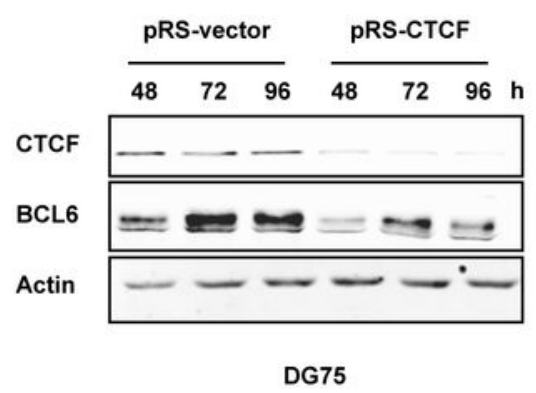

d

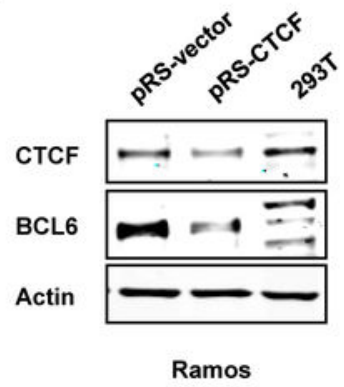

f

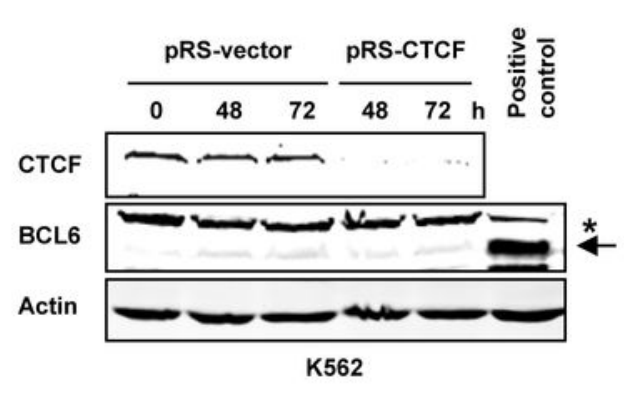

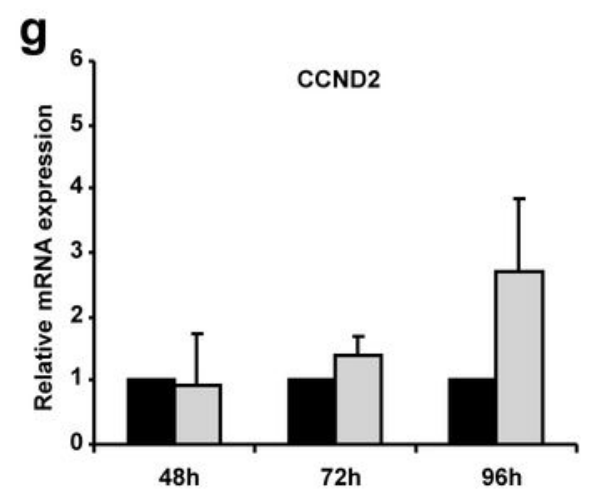

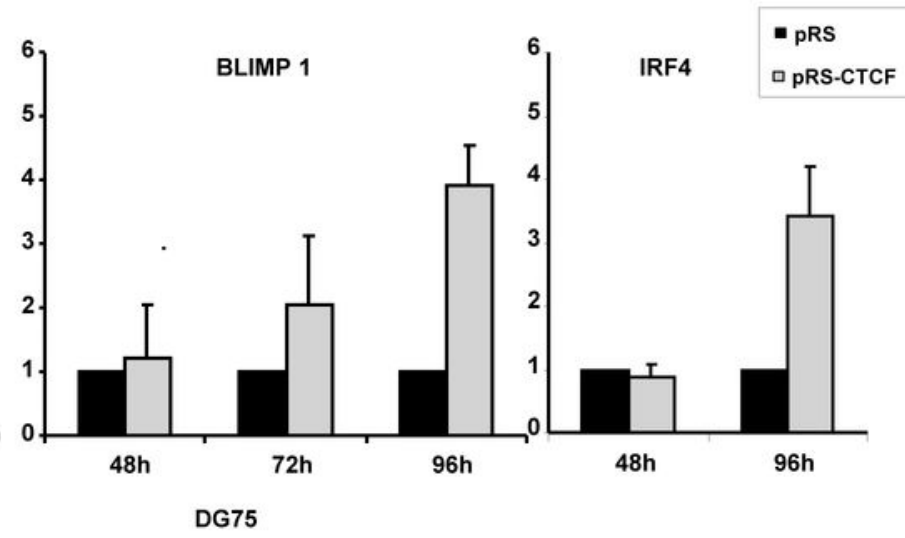


Figure 4

\section{Batlle-López, A. et al}

a
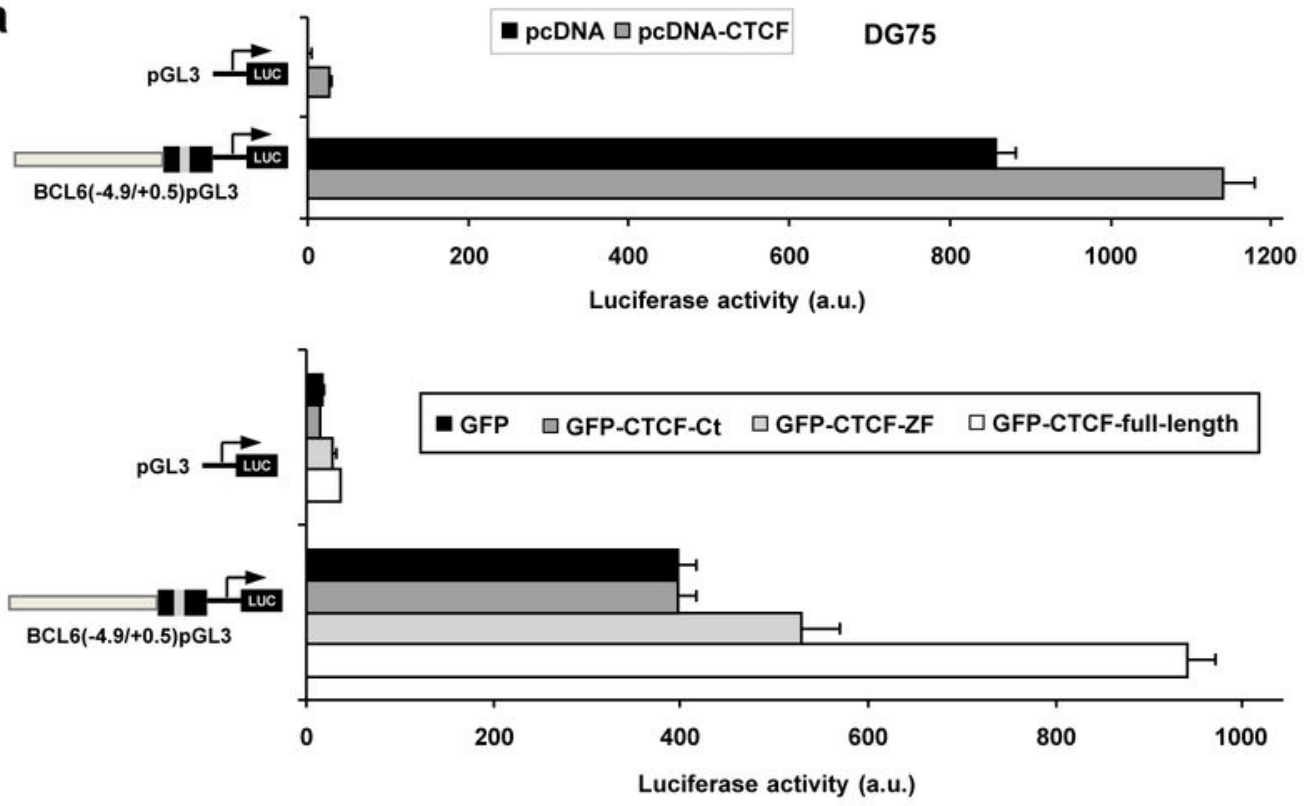

b

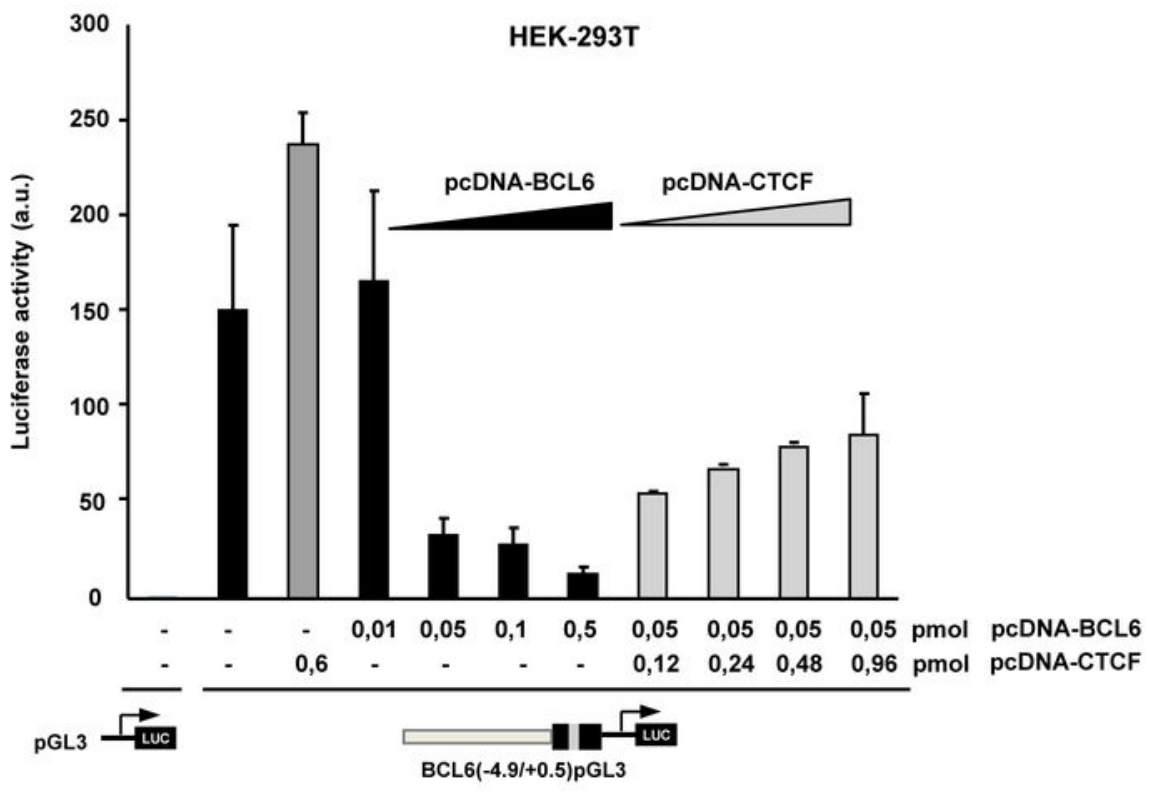


Figure 5

Batlle-López, A. et al
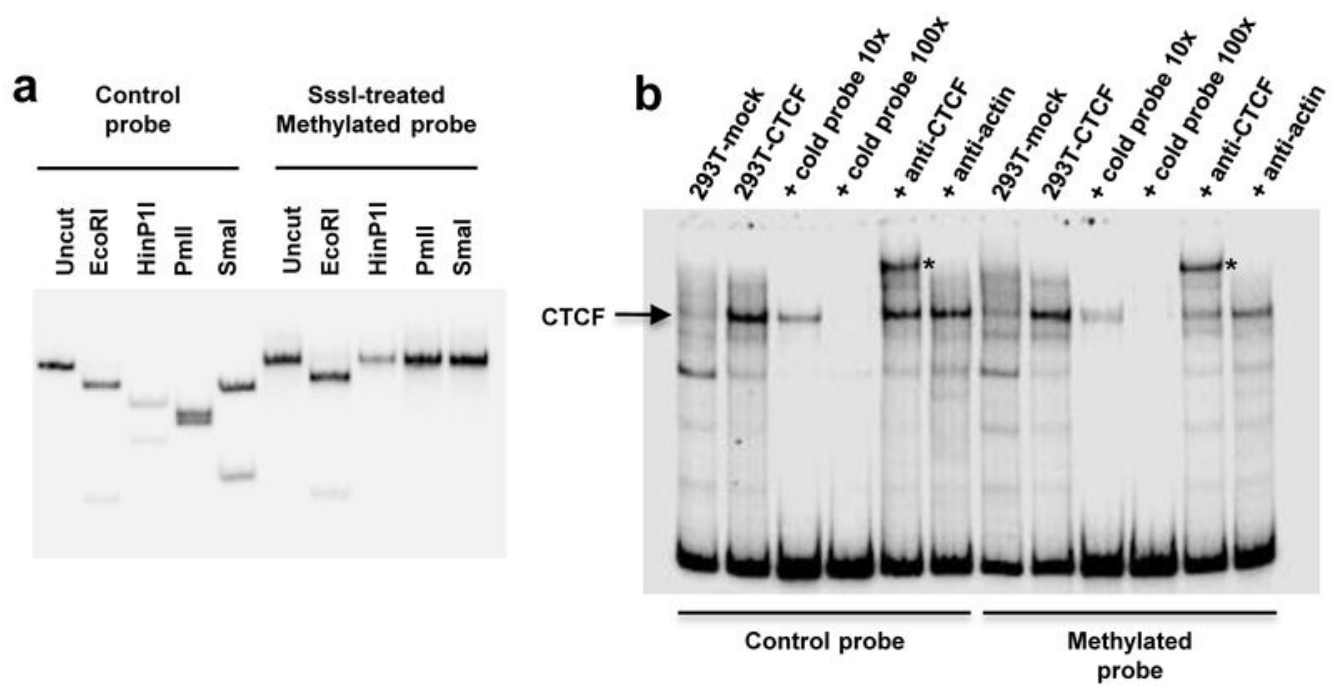

C
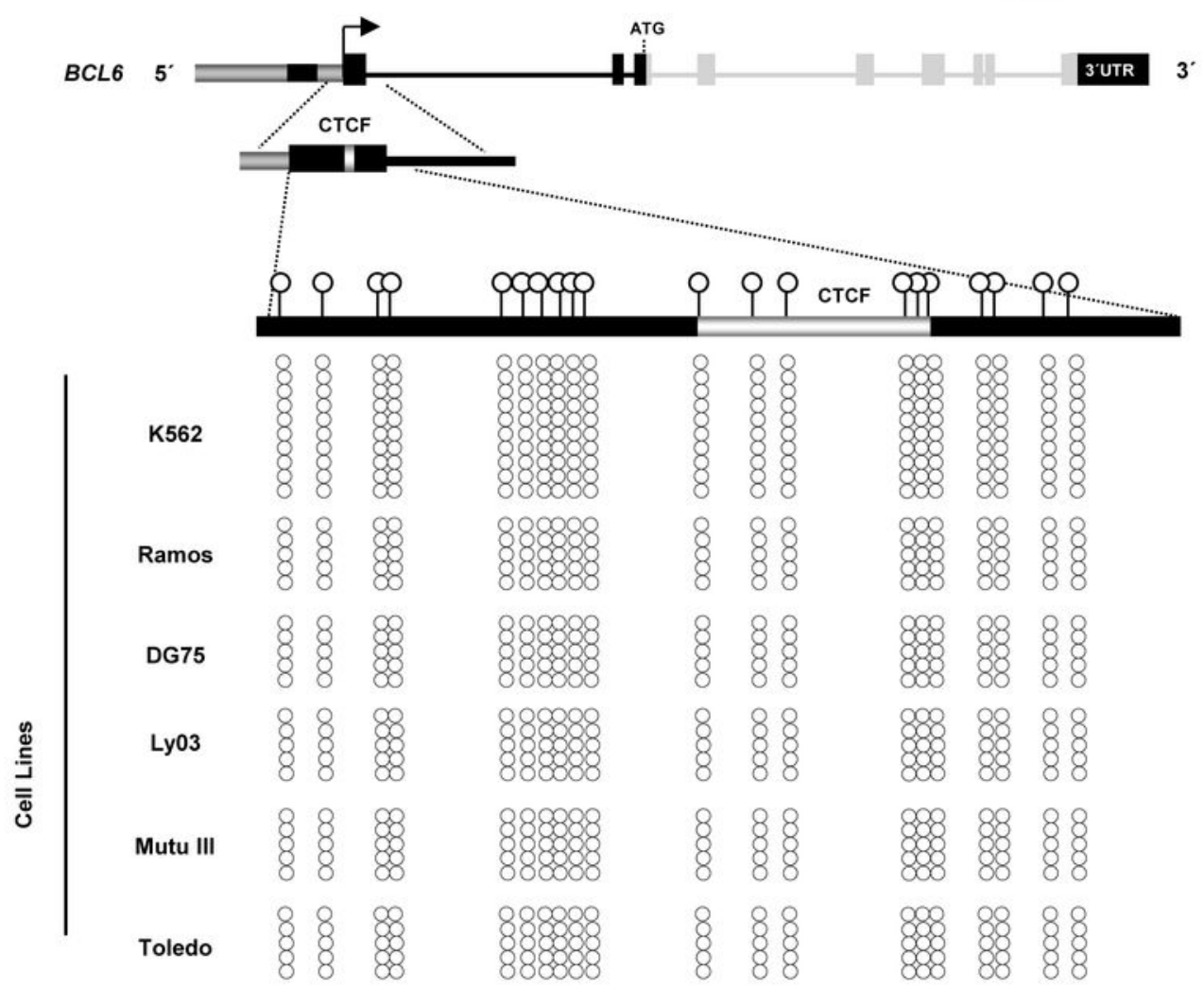

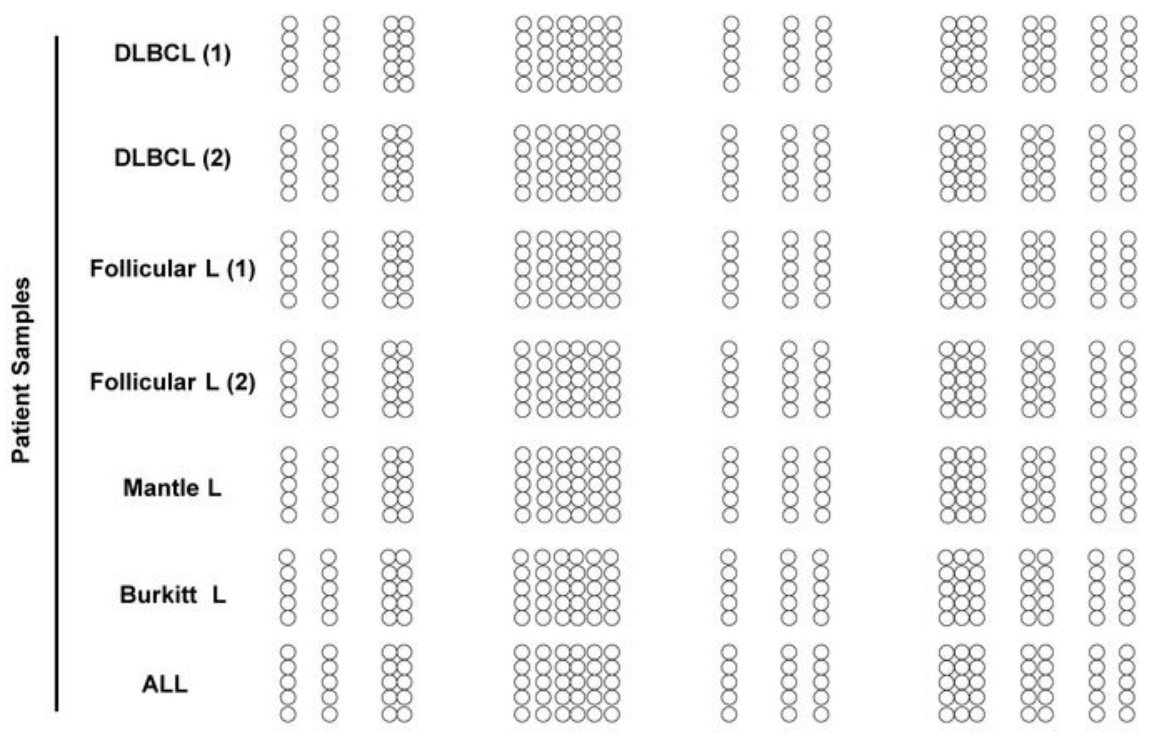


Figure 6

a

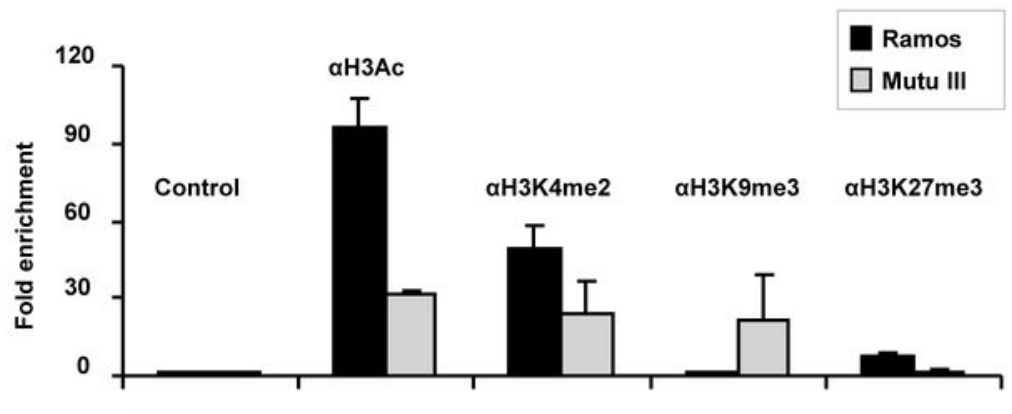

BCL6 exon1A

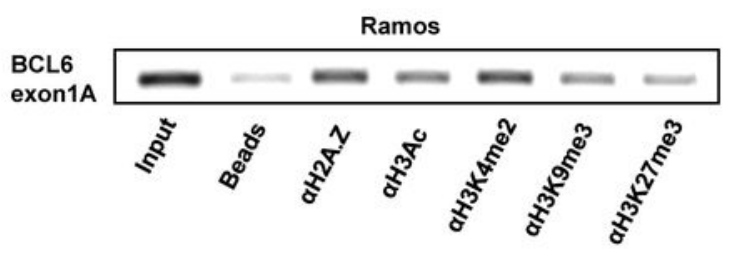

b

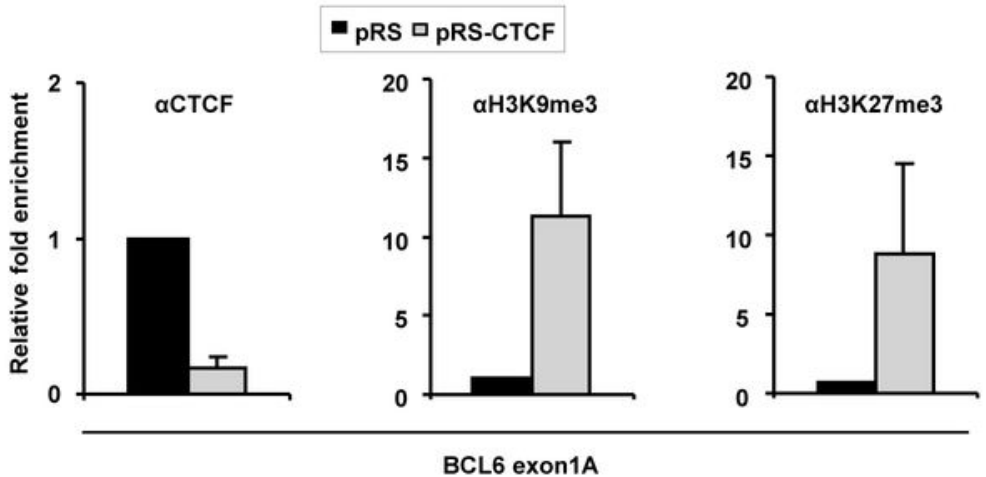

BCL6
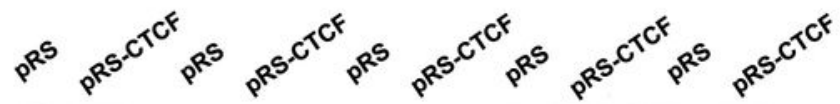

exon1A

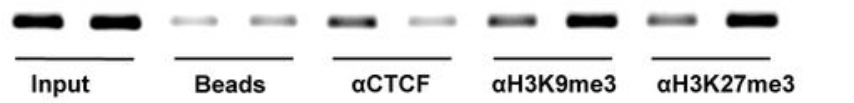




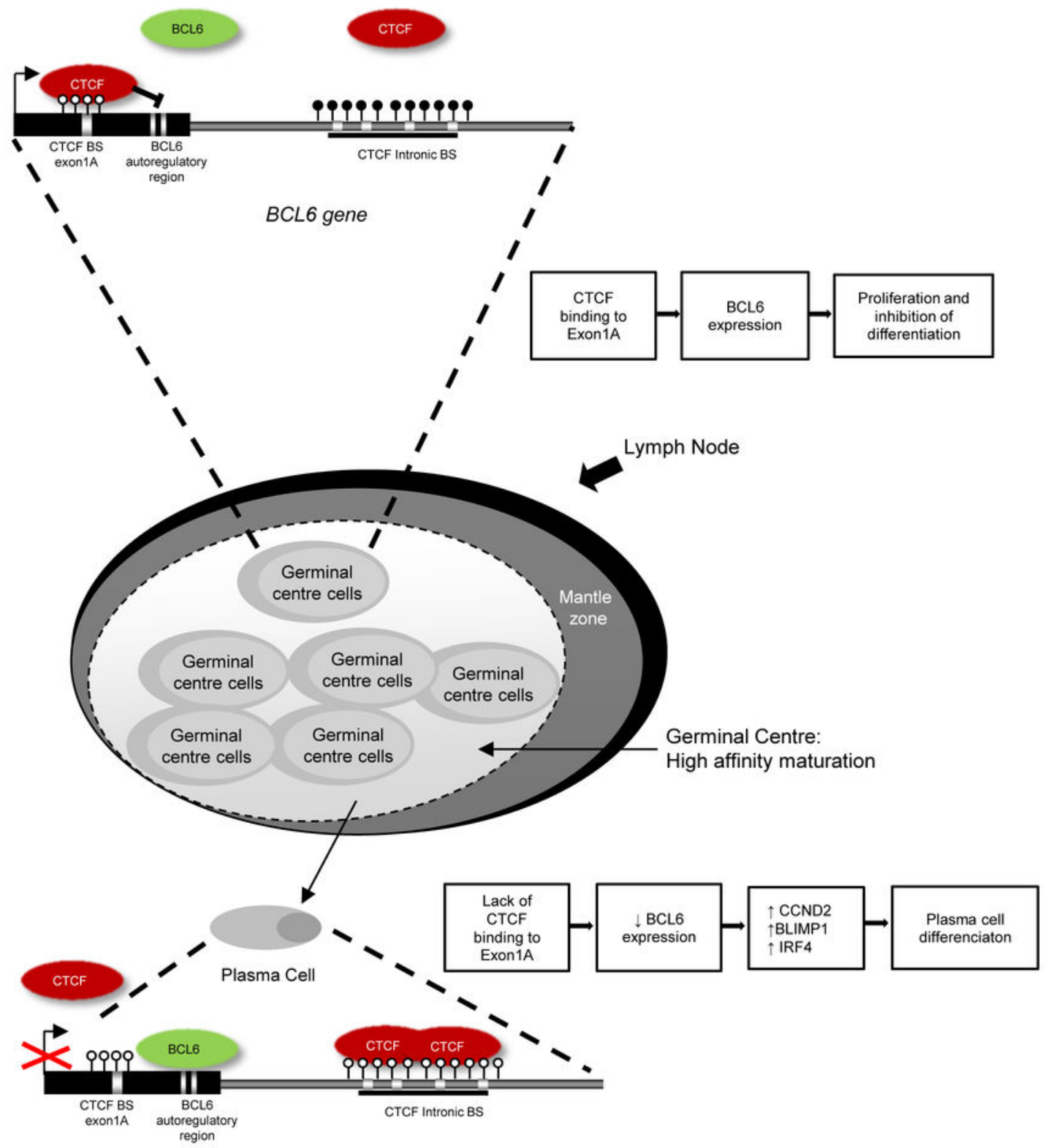




\section{Supplementary Information}

Novel CTCF binding at a site in exon 1A of BCL6 is associated with active histone marks and a transcriptionally active locus". Ana Batlle-López, María G. Cortiguera, Manuel Rosa-Garrido, Rosa Blanco, Elida del Cerro, Verónica Torrano, Simon D. Wagner and M. Dolores Delgado,

a

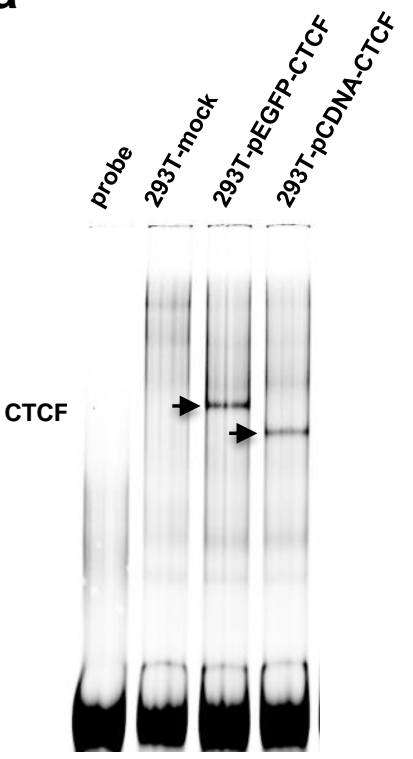

b

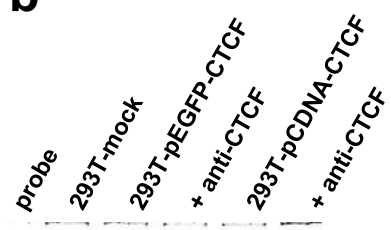

CTCF

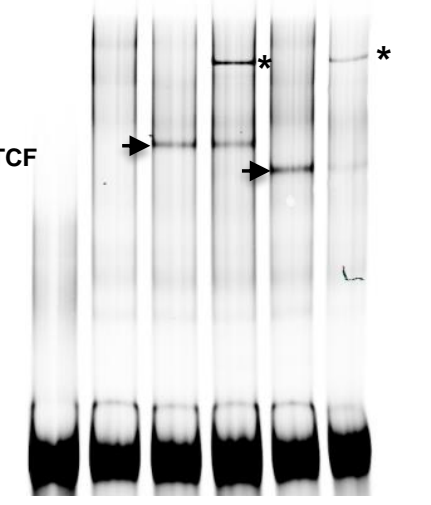

CGGAGCAGGCCATACCATCGTCTTGGGCCCGGGGAGGGAGAGCCACCTTCAGGCCCCTCGAGCCTCGAACCGGAACCTCCAAATC

Supplementary Figure S1. EMSA to delimitate the CTCF binding site at to BCL6 exon 1A. A $80 \mathrm{nt}$ double-stranded oligonucleotide (sequence indicated above) containing the predicted "core" 20 nt CTCF binding site (sequence in red) was used as a probe. Probe was labelled 5' with IRDye700 and image was visualized with an Odyssey infrared-imaging system (Li-Cor

Biosciences) a) Nuclear extracts were obtained from mock transfected 293T cells or from 293T transfected with $\mathrm{pEGFP-CTCF}$ full length or with $\mathrm{PCDNA-CTCF}$ expression vectors as indicated. The CTCF shifted bands are shown by arrows (note a more retarded complex corresponding to the fusion protein EGFP-CTCF in comparison with the pCDNA-CTCF). b) Nuclear extracts were obtained as in a). For supershift experiments, an anti-CTCF antibody was added (asterisk, supershifted bands). 


\section{Supplementary Information}

Novel CTCF binding at a site in exon 1A of BCL6 is associated with active histone marks and a transcriptionally active locus". Ana Batlle-López, María G. Cortiguera, Manuel Rosa-Garrido, Rosa Blanco, Elida del Cerro, Verónica Torrano, Simon D. Wagner and M. Dolores Delgado,

a

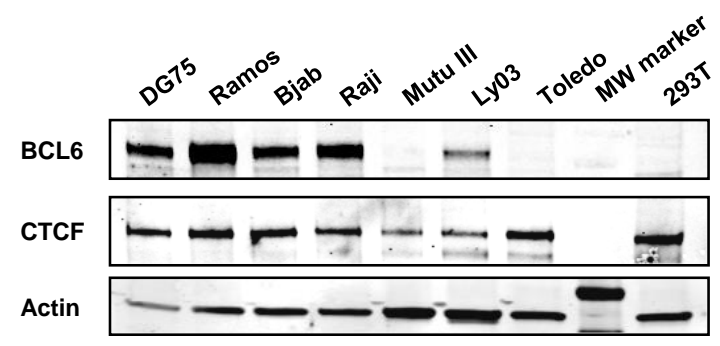

b

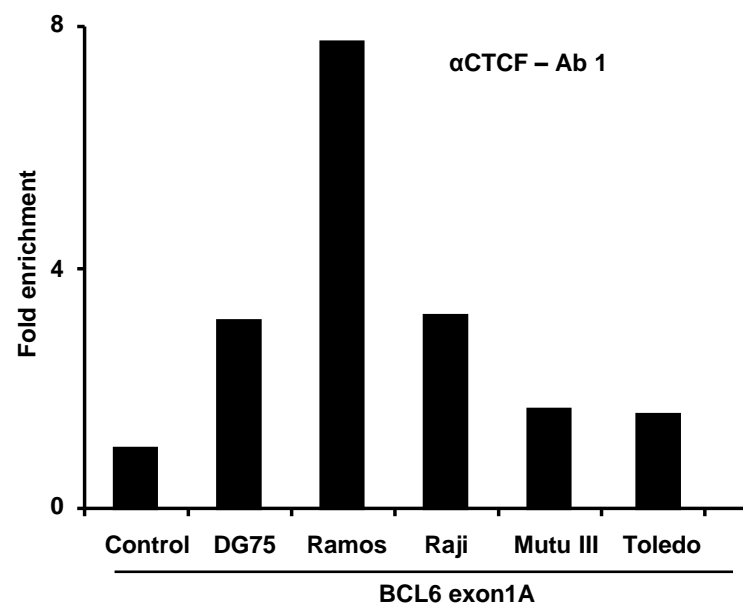

Supplementary Figure S2. BCL6 expression and CTCF occupancy in lymphoma cell lines. (a) Western blot showing BCL6 and CTCF protein expression in several lymphoma cell lines. Actin was used as loading control. (b) ChIP performed in the indicated cell lines to analyse CTCF relative enrichment at the BCL6 exon1A. A representative experiment is shown. 


\section{Supplementary Information}

Novel CTCF binding at a site in exon 1A of BCL6 is associated with active histone marks and a transcriptionally active locus". Ana Batlle-López, María G. Cortiguera, Manuel Rosa-Garrido, Rosa Blanco, Elida del Cerro, Verónica Torrano, Simon D. Wagner and M. Dolores Delgado,
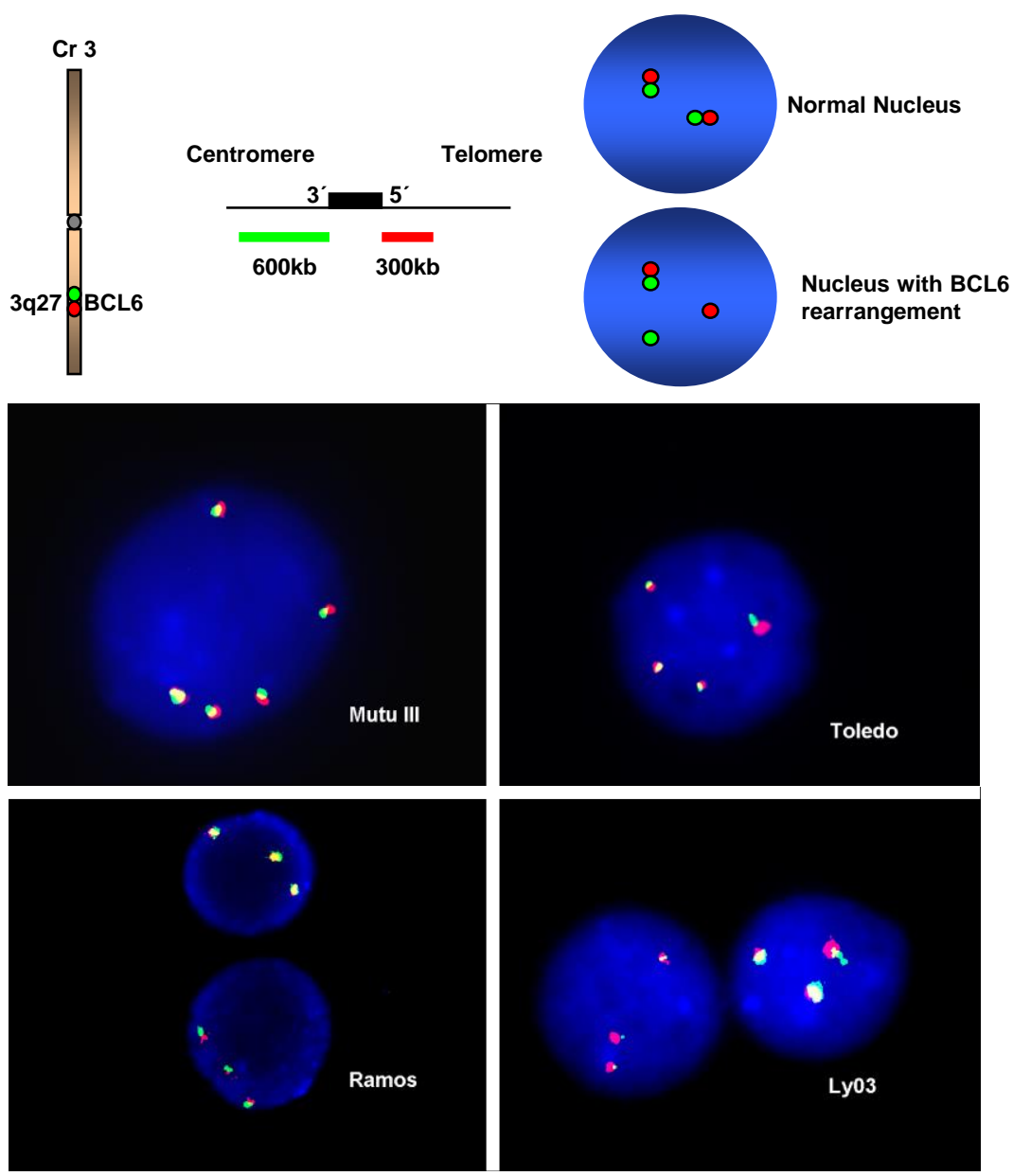

\section{Supplementary Figure S3. BCL6 locus status in lymphoma cell lines.}

BCL6 is a frequent target of chromosomal translocations with many different partners. These translocations often cluster in a $4 \mathrm{~kb}$ region on the BCL6 gene known as the major breakpoint region (MBR) or major translocation cluster (MTC) spanning the promoter, the first non-coding exon and the 5' part of the first intron. As a result of these rearrangements transcription of the unaltered BCL6 coding region is controlled by the regulatory sequences of the partner gene (promoter substitution), leading to deregulated BCL6 expression. Thus, in order to find a possible correlation between BCL6 protein expression profile and CTCF occupancy at the BCL6 locus, BCL6 gene rearrangements were investigated in cell lines and also in patients included in this study by fluorescence in situ hybridization (FISH), following standards procedures. Briefly, metaphase/interphase preparations from the methanol/acetic acid-fixed cell suspensions were hybridized using a LSI BCL6 (3q27) Dual color Break apart probe (Vysis-Abbott, Downers Grove, IL, ref 32-191016). Nuclei were scored as rearranged if at least one split orange-green signal was observed. Gains were reported when three or more fusion signals were observed. Control values were previously established based on samples of 10 controls $\mathrm{X} \pm 3 \mathrm{D}$.S. = mean plus three standard deviations. None of the cell lines utilized on this study showed rearrangement of the BCL6 gene. However, a number of cell lines, including those with undetectable protein expression such as Mutu III cells, showed gains of the BCL6 locus, suggesting that additional mechanisms on the regulation of BCL6 expression must be operative. 


\section{Supplementary Information}

Novel CTCF binding at a site in exon 1A of BCL6 is associated with active histone marks and a transcriptionally active locus". Ana Batlle-López, María G. Cortiguera, Manuel Rosa-Garrido, Rosa Blanco, Elida del Cerro, Verónica Torrano, Simon D. Wagner and M. Dolores Delgado,

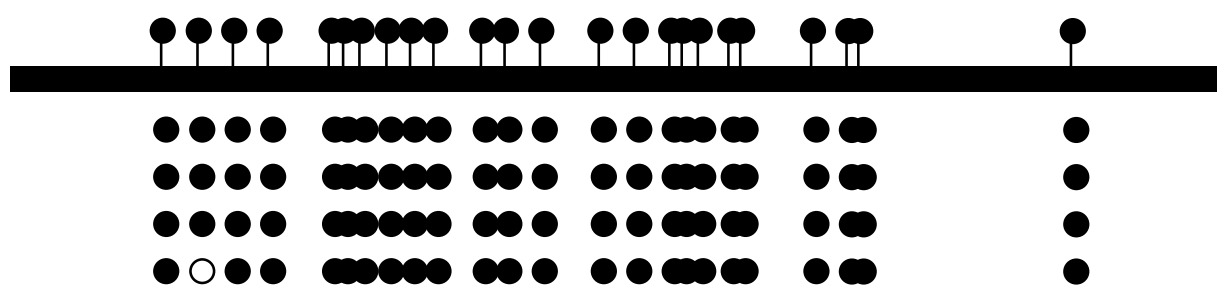

Supplementary Figure S4. Positive control for the bisulfite transformation assay and the ability to detect methylated DNA. Enzymatically methylated genomic DNA was purchased (Cat D5511; Zymo research), bisulfite converted and PCR amplified using the primer set provided with the control kit set. The PCR product was purified and cloned on the PGMT vector. Four clones were sent for sequencing. 


\section{Supplementary Information}

Novel CTCF binding at a site in exon 1A of BCL6 is associated with active histone marks and a transcriptionally active locus". Ana Batlle-López, María G. Cortiguera, Manuel Rosa-Garrido, Rosa Blanco, Elida del Cerro, Verónica Torrano, Simon D. Wagner and M. Dolores Delgado,

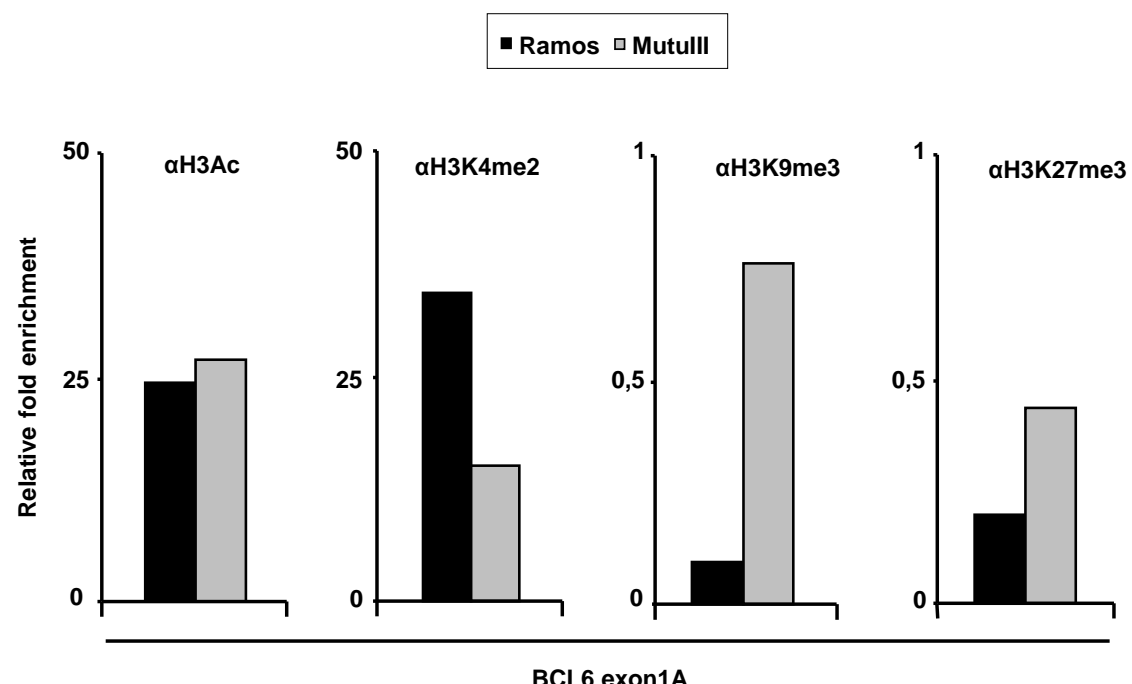

Supplementary Figure S5.ChIP controls for specific chromatin states. Primers for open and closed chromatin states were obtained from the ChIP-IT qPCR analysis kit (Active motif North America; ref 53029). Relative fold enrichment of positive histone marks ( $\mathrm{H} 3 \mathrm{Ac}$ and $\mathrm{H} 3 \mathrm{~K} 4 \mathrm{me} 2)$ were divided by the relative fold enrichment on a close chromatin locus. On the contrary, relative fold enrichment of repressive histone marks (H3K9 and H3K27) on exon1A were divided by the relative fold enrichment of those marks on an open chromatin locus (GAPDH). 


\section{Supplementary Information}

Novel CTCF binding at a site in exon $1 \mathrm{~A}$ of BCL6 is associated with active histone marks and a transcriptionally active locus". Ana Batlle-López, María G. Cortiguera, Manuel Rosa-Garrido, Rosa Blanco, Elida del Cerro, Verónica Torrano, Simon D. Wagner and M. Dolores Delgado,

a) GM12878 lymphoblastoid cell line

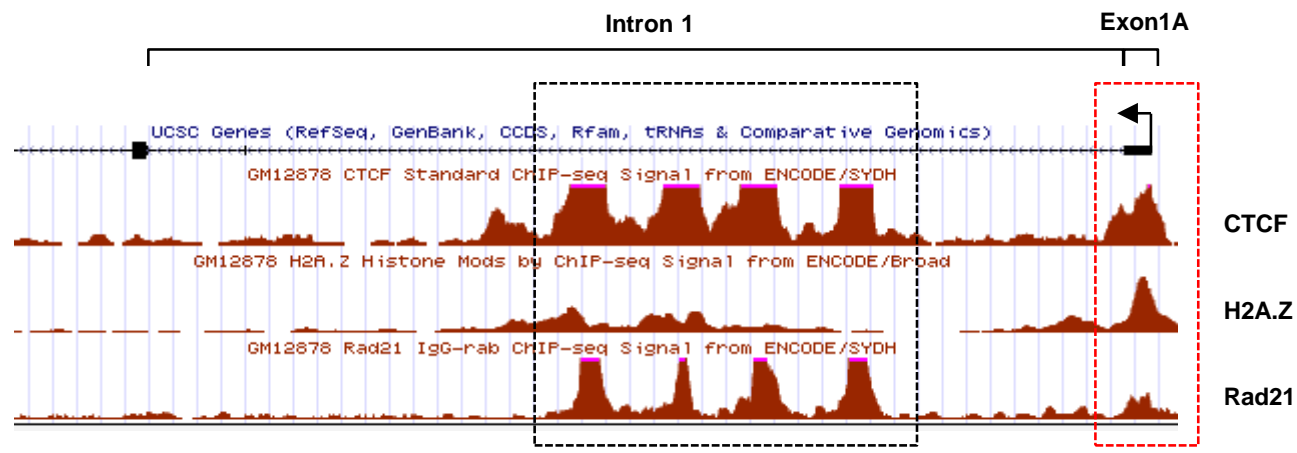

b) K562 myeloid cell line

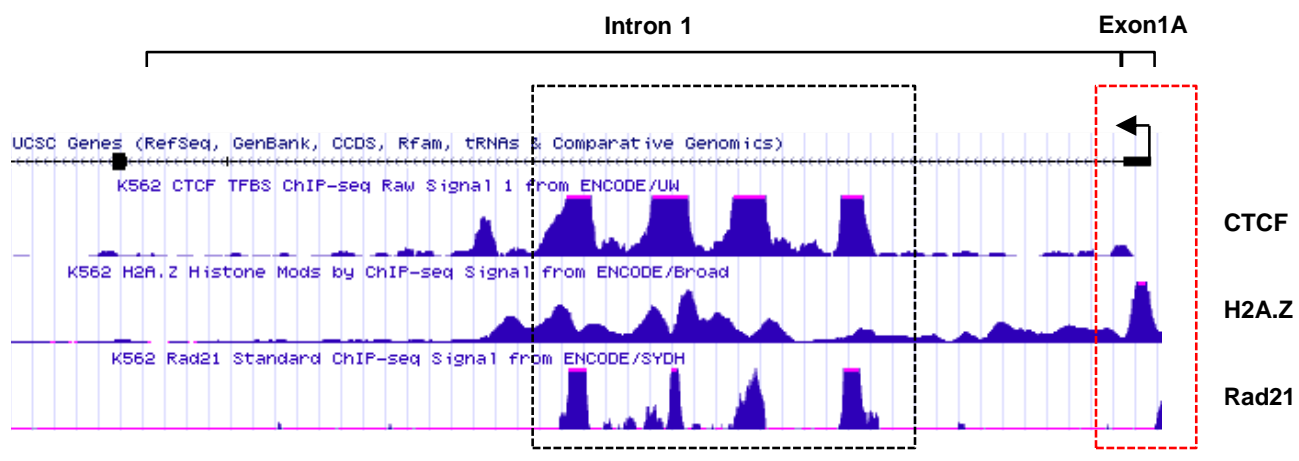

Supplementary Figure S6. ENCODE ChIP-seq data confirmed CTCF binding site within BCL6 exon1A in GM12878 but not in K562 cell line. Shown are the ChIP-seq profiles of CTCF, H2A.Z and Rad21 for BCL6 gene on chromosome 3 from GM12878 and K562 cell lines. a) No data of CTCF ChIP-seq in the lymphoma cell lines used in our study were found using ENCODE. However, CTCF binding to exon $1 \mathrm{~A}$ was found in lymphoblastoid cells such as the GM12878 line. Binding of H2A.Z and the cohesin subunit Rad21 were also found in BCL6 exon1A, confirming our data in lymphoma cell lines (Red square). b) In agreement with our data, no enrichment of CTCF in exon1A was found in the K562 myeloid cell line (Red square). CTCF binding sites in BCL6 intron 1, described by Lai et al and Ramachandrareddy et al. are also shown (Black squares). 


\section{Supplementary Information}

Novel CTCF binding at a site in exon 1A of BCL6 is associated with active histone marks and a transcriptionally active locus". Ana Batlle-López, María G. Cortiguera, Manuel Rosa-Garrido, Rosa Blanco, Elida del Cerro, Verónica Torrano, Simon D. Wagner and M. Dolores Delgado,

\section{Supplementary Table S1. Cell lines used}

\begin{tabular}{|c|c|c|c|c|}
\hline $\begin{array}{l}\text { CELL LINE } \\
\text { NAME }\end{array}$ & PHENOTYPE & $\begin{array}{l}\text { BCL6 expression } \\
\text { (Supp Figs2) }\end{array}$ & $\begin{array}{l}\text { CULTURE } \\
\text { MEDIUM }\end{array}$ & SOURCE \\
\hline RAMOS & $\begin{array}{l}\text { Human Burkitt's } \\
\text { Lymphoma EBV } \\
\text { negative }\end{array}$ & +++ & RPMI-10F & * \\
\hline DG75 & $\begin{array}{l}\text { Human Burkitt's } \\
\text { Lymphoma EBV } \\
\text { negative }\end{array}$ & +++ & RPMI-10F & * \\
\hline BJAB & $\begin{array}{l}\text { Human Burkitt's } \\
\text { Lymphoma EBV } \\
\text { negative }\end{array}$ & ++ & RPMI-10F & * \\
\hline RAJI & $\begin{array}{l}\text { Human Burkitt's } \\
\text { Lymphoma EBV } \\
\text { positive }\end{array}$ & ++ & RPMI-10F & * \\
\hline MUTU III & $\begin{array}{c}\text { Human Burkitt's } \\
\text { Lymphoma EBV } \\
\text { negative }\end{array}$ & - & RPMI-10F & $\begin{array}{c}\text { Dr. Noémi Nagy } \\
\text { (MTC; Karolinska Institute. }\end{array}$ \\
\hline TOLEDO & Human DLBCL & - & RPMI-20F & Dr. A Piris( CNIO; Madrid) \\
\hline LYO3 & Human DLBCL & + & RPMI-20F & Dr. A Piris (CNIO ;Madrid) \\
\hline K562 & $\begin{array}{l}\text { Human CML -BC } \\
\text { (p210 BCR-ABL) }\end{array}$ & - & RPMI-10F & ATCC \\
\hline HEK293T & $\begin{array}{c}\text { Human Embryonic } \\
\text { Kidney }\end{array}$ & - & DMEM-10F & * \\
\hline
\end{tabular}

*These cell lines were already in the laboratory.

Abbreviatures:

F: Fetal Calf serum

EBV: Epstein Barr Virus

Burkitt's: Lymphoma:B cell Lymphoma

DLBCL: Diffuse Large B Cell Lymphoma

CML BC: Blast Crisis of Chronic Myeloid Leukaemia 


\section{Supplementary Information}

Novel CTCF binding at a site in exon 1A of BCL6 is associated with active histone marks and a transcriptionally active locus". Ana Batlle-López, María G. Cortiguera, Manuel Rosa-Garrido, Rosa Blanco, Elida del Cerro, Verónica Torrano, Simon D. Wagner and M. Dolores Delgado,

Supplementary Table S2. List of primers used.

\begin{tabular}{|c|c|c|}
\hline Name & Sequence & Use \\
\hline BCL6 & $\begin{array}{l}\text { 5'-AGAGCCCATAAAACGGTCCT-3' } \\
\text { 5'-AGTGTCCACAACATGCTCCA-3' }\end{array}$ & RT-qPCR \\
\hline CTCF & $\begin{array}{l}\text { 5'-TTACACGTGTCCACGGCGTTC-3' } \\
\text { 5'-GCTTGTATGTGTCCCTGCTGGCA-3'; }\end{array}$ & RT-qPCR \\
\hline RPS14 & $\begin{array}{l}\text { 5'-GGGGTGACATCCTCAATCC-3' } \\
\text { 5'-TATCACCGCCCTACACATCA-3'. }\end{array}$ & RT-qPCR \\
\hline CCND2 (cycD2) & $\begin{array}{l}\text { 5'-TGAGCTGCTGGCTAAGATCA-3' } \\
\text { 5'-ATATCCCGCACGTCTGTAGG-3' }\end{array}$ & RT-qPCR \\
\hline BLIMP1/PRMD1 & $\begin{array}{l}\text { 5'-CTGAGAGTGCACAGTGGAGA-3' } \\
\text { 5'-TGGGTCTTGAGATTGCTGGT-3' }\end{array}$ & RT-qPCR \\
\hline IRF4/MUM1 & $\begin{array}{l}\text { 5'-GTGTGGGAGAACGAGGAGAA-3' } \\
\text { 5'-TTGTACGGGTCTGAGATGTCC-3' }\end{array}$ & RT-qPCR \\
\hline BCL6-exon 1A & $\begin{array}{l}\text { 5'-GCACTCCCCCTCTTATGTCA-3' } \\
\text { 5'-GATTTGGAGGTTCCGGTTC-3'. }\end{array}$ & EMSA \\
\hline MYC-N & $\begin{array}{l}\text { 5'-ACAAGGAGGTGGCTGGAAAC-3' } \\
\text { 5'-TTCСССTCСTGGCTTTTAGT-3' }\end{array}$ & EMSA \\
\hline BSP & $\begin{array}{l}\text { 5'GGAGGGAGAGTTATTTTTTAGGT-3' } \\
\text { 5'-ACAACAACAACAATAATCACCT-3'. }\end{array}$ & $\begin{array}{l}\text { Bisulfite } \\
\text { Sequencing }\end{array}$ \\
\hline hMLH1 & $\begin{array}{l}\text { 5' - GGAGTGAAGGAGGTTACGGGTAAGT - 3' } \\
5^{\prime} \text { - AAAAACGATAAAACCCTATACCTAATCTATC- 3' }\end{array}$ & $\begin{array}{l}\text { Bisulfite } \\
\text { Sequencing }\end{array}$ \\
\hline-2398 (1) BCL6 & $\begin{array}{l}\text { 5'-CCCACTCTGGCTGGTTCTAC-3' } \\
\text { 5'-TGTCAAAACTGCCATTCAGC -3' }\end{array}$ & ChIP \\
\hline-1216 (2) BCL6 & $\begin{array}{l}\text { 5'-GCTGCTTCTGGTCCAAACAT-3' } \\
\text { 5'-AAGTCCCTACTCATCCTCCC-3'; }\end{array}$ & ChIP \\
\hline-476 (3) BCL6 & $\begin{array}{l}\text { 5'-CTGCACTGCAATTGCCTTTA-3' } \\
\text { 5'-CTGACACGACGCACATCACG-3' }\end{array}$ & ChIP \\
\hline+80 (4) BCL6 & $\begin{array}{l}\text { 5'-CACTTCAGCAAAAGTCCAAGG-3' } \\
\text { 5'-CTATCCCTTTCTTTTCCGTGC-3' }\end{array}$ & ChIP \\
\hline+257 (5) BCL6 & $\begin{array}{l}\text { 5'-GCACTCCCCCTCTTATGTCA-3' } \\
\text { 5'-GATTTGGAGGTTCCGGTTC-3' }\end{array}$ & ChIP \\
\hline +4542 (6) BCL6 & $\begin{array}{l}\text { 5'- CCAGCAGTCTTGGAGGATTT-3' } \\
\text { 5'- ACAGACCAGCCTACCATTGC -3'; }\end{array}$ & ChIP \\
\hline +4970 (7) BCL6 & $\begin{array}{l}\text { 5'- CCAGCAGTCTTGGAGGATTT-3' } \\
\text { 5'- GAAGGGGAAGAGAGCGATTT-3'; }\end{array}$ & ChIP \\
\hline H42.1 rDNA & $\begin{array}{l}\text { 5'- GCTTCTCGACTCACGGTTTC-3' } \\
\text { 5'-CCGAGAGCACGATCTCAAA-3 }\end{array}$ & ChIP \\
\hline MYC-H.1 & $\begin{array}{l}\text { 5'-CAACGCAACACAGGATATGG-3' } \\
\text { 5'-TTCCССTCCTGGCTTTTAGT-3 }\end{array}$ & ChIP \\
\hline
\end{tabular}

